\title{
Bir Cümleden Oluşan Kazakça Atasözlerindeki Öge Dizimleri ve Bu Öge Dizimlerinin Sıklık Dağılımları
}

\author{
The Word Orders of the Single-Sentence Kazakh Proverbs and Frequency \\ Distributions of These Word Orders
}

\section{Murat CERÍTOĞLU *}

Öz: Herhangi bir istatistiki çalışmaya dayanmadan, Türk dilinin ölçünlü öge diziminin Ö/N/Y olduğu varsayılır. Ayrıca, çalkalayan bir dil olmasından dolayı, Türk dilinde Ö/Y/N, N/Ö/Y, N/Y/Ö, Y/Ö/N ve Y/N/Ö öge dizimiyle de cümleler kurulabileceği öngörülür. Bu çalışmada, bu öngörü ve varsayımların Kazakça konuşurlarının öge dizimi bakımından eş zamanlı ve art zamanlı ortak cümleleri olan atasözlerinin öge dizimleriyle ne ölçüde örtüştüğü istatistiki olarak belirlenmeye çalışıldı. Bunun için Kazakçaya ait tek cümleden oluşan 2726 atasözünün öge çözümlemesi yapıldı. Çözümlenen atasözleri yüklemin türü ve çalkalanması, öznenin bağımsız biçimbirim olarak var olup olmaması dikkate alınarak öge dizimlerine göre sınıflandırıldı. Sınıflandırılan öge dizimlerinin dizi sıklıkları belirlendi ve sıklık dağılımları istatistiksel olarak değerlendirildi. Değerlendirilme sonucunda özne, tümleç ve yüklem ögelerinden oluşan Kazakça atasözlerinde öge dizimi eğiliminin N/Ö/Y diziminden yana olduğu istatistiki olarak belirlendi, yüklemle başlayan öge diziminin bulunmadığı tespit edildi. Ayrıca, Türk dilinde özne ve nesne tümlecinin cümlede yer alması cümle kurucunun tasarrufunda olduğu için, bu ögelerin eksiltildiği cümlelerin öge dizimi ve eğilimlerinin tespitinde, öngörülen ve varsayılan öge dizimlerinin yetersiz kaldığı görüldü.

Anahtar sözcükler: Kazakça Atasözleri, Çalkalama, Söz Dizimi, Öge Dizimi, Ölçünlü Öge Dizimi

Abstract: Without base on any statistical work, it is assumed that the canonical word order of the Turkic language is SOV. It is foreseen that the sentence can be established in the word order of SVO, OVS, OVS, VOS and VOS in Turkic language. This study was done to determine statistically whether predictions and assumptions to coincided with the word orders of proverbs which are synchronic and diachronic common sentences of Kazakh speaking. For this, the element analysis of 2726 Kazakh proverbs with a single sentence was made. The analyzed proverbs are classified according to the location in sentence and the type of the predicate, to whether or not the subject exists as an independent morpheme. The paradygma frequencies of the classified syntagma were determined and evaluated statistically. As a result of the evaluation, it has been determined that the tendency of word order is in the OSV order in the Kazakh proverbs composed of the subject, the object, and the predicate. It has been determined that there isn't word order in which the predicate is the first element. In addition, since the inclusion of the subject and object complements in the Turkic languages was in the saving of the sentence builder, it was seen that the predicted and default word orders are insufficient in the determination tendencies of word order and word order of the sentences in which these elements were lacking.

Keywords: Kazakh Proverbs, Scrambling, Syntax, Word Order, Canonical Word Order

\footnotetext{
* Doç. Dr., Ankara Üniversitesi, DTCF, Çağdaş Türk Lehçeleri ve Edebiyatları Bölümü, Ankara. ceritoglu@ankara.edu.tr

Bu çalışma, 1-7 Haziran 2018 tarihinde Ulanbator-Moğolistan'da gerçekleştirilen "Köktürk Yazısının Okunuşunun 125. Yılında Orhun'dan Anadolu'ya Uluslararası Türkoloji Sempozyumu”unda sözlü olarak sunulan bildirinin gözden geçirilmiş ve düzenlenmiş şeklidir.
} 
Bu çalışmada amaç, Kazakça atasözü olan cümlelerdeki öge dizimi eğilimlerini tespit etmek ve tespit edilen öge dizimlerini Türk dili için varsayılan ölçünlü öge dizimiyle (conanical word order) ve öngörülen öge dizimleriyle karşılaştırarak tartışmaktır. Çalışma, iki veya daha fazla cümleden oluşan atasözlerinde bir cümlede bulunan öge veya öge dizimi kalıbının diğer cümledeki öge veya öge dizimi kalıbını etkileyebileceği düşüncesinden dolayı, bir cümleden oluşan atasözleriyle (Kazak Türklerine ait olan ve edebi açıdan halk biliminin inceleme alanında bulunan sözlü türler, 2004-2013 yılları arasında basılan 100 ciltlik Babalar Sözi külliyatında yayımlanmıştır. Bu 100 ciltlik Babalar Sözi külliyatının 65, 66, 67, 68 ve 69. ciltleri atasözlerini içermektedir. 65. ciltte, M. Avezov Edebiyat ve Sanat Enstitüsü ile Merkezi Bilim Kütüphanesinin nadir eserler bölümlerinde saklanan eserler temel alınarak derlenmiş olan atasözleri yer alır. Bu ciltte, konularına göre sınıflandırılmış 6077 atasözü sıralanır. Bu atasözlerinden 2726's1 bir cümleden oluşmaktadır. İnceleme bir cümleden oluşan bu 2726 atasözü üzerinde yapılmıştır) sınırlandırılmıştır.

Anlamlı veya işlevli birimler oluşturacak biçimde (Karaağaç 2013, 334), dil birimlerinin belirli kurallar esasında yatay siralanması (Bussmann 1996, 855) dizim (syntagma) olarak adlandırılır. Aynı dizimle kurulan dil birimlerine ise, dizi (paradigma) denir. Bir dilin farklı konuşurları tarafından kurulan cümleler, belirli öge dizimi kalıplarının dizileridir.

Türk dilinin öge diziminde özne, yüklem ve yüklemin yönetim alanına yardımcı biçimbirimler aracılığıyla giren ögelerin konumu, farklı derecelerde de olsa serbesttir. Bu ögelerin cümle içindeki konumları dil kullanıcısının tasarrufuna bağlı olarak değişebilir. Yüklemin yönetim alanına sıfır biçimbirimle giren belirtisiz nesne tümleci ile yer, durum veya miktar ifade eden zarf tümleçlerinin dizimdeki konumu ise kısıtlıdır. Böylesi ögeler yüklemin hemen yanında yer alır, yüklemle birlikte cümle içindeki konumları değiştirilebilir.

Bir ögenin cümledeki konumunun serbestliği (Ross 1967, 71; Bussman 1996, 1033; Crystal 2008, 425), değişkenliği genel dil biliminde çalkalama (scrambling) olarak adlandırılır. Özellikle özne, yüklem ve nesne tümlecinin öge dizimindeki konumlarının sürekliliği dikkate alınarak diller, çalkalayan diller ve çalkalamayan diller olarak sınıflandırılır. Türk dili; Japonca, Korece, Farsça, Hintçe-Urduca, Macarca, Rusça, Lehçe, Çekçe, Fince, Almanca, Hollandaca, İtalyanca, Yunanca, Latinceyle (Sekerina 1997, 2; Yavuz 2012, 45) birlikte, çalkalayan diller arasında sayllır.

Türk dilindeki olağan cümlelerde ögeler bazı kısıtlamalarla çalkalanabilirken atasözü olan cümlelerde çalkalanmaz. Atasözü olan cümlenin de olağan cümlenin de kuruluşu söz dizimsel ilişki yöntemleri esasında gerçekleşir. Atasözü olan cümle veya cümleler birliğini olağan cümlelerden ayıran söz dizimsel fark, öge dizimlerinin kalıplaşmış olmasıdır. Sözlü veya yazılı iletişim sürecinde kurulan ve yapısında yer alan sözlerin anlamlarının cümle anlamıyla doğrudan ilgisi bulunan olağan cümlelerdeki ögeler, çeşitli sebeplerden dolayı dil kullanıcısı tarafindan çalkalanabilir. Atasözü olan cümlelerde ise, cümledeki ögeler, kim olursa olsun cümle kurucu tarafından çalkalanmaz. Atasözleriyle birlikte kalıplaşmış dil birimi sayılan deyimler, ikilemeler ve kalıp sözlerde (Gökdayı 2008, 89) de öge çalkalanması görülmez.

Atasözü olan cümlelerdeki öge diziminin sürekliliği, türemiş sözlerdeki eklerin dizim sürekliliğine benzer. Atasözü olan cümleler de türemiş sözler de daha önceden belirlenmiş kurucu birim dizimleriyle söz varlığında kullanılmaya hazır dururlar. Dilde gösterge olarak kullanılan her iki birimde de kurucu dil birimlerinin çalkalanması, başlangıçta sahip olunan gösteren-gösterilen ilişkisini, zayıflatır, hatta ortadan kaldırır. Türemiş söz, farklı bir türemiş söze (gözlükçü/gözcülük, sözlükçü/sözcülük, sözlüklü/sözlülük, odunluklu/odunluluk); atasözü olan cümle, olağan cümleye (damlaya damlaya göl olur - göl damlaya damlaya olur) dönüşür. 
Hem cümlede yer alacak sözlerin hem de öge diziminin belirlenmesinde kişisel dil kullanıcısının etkisi, olağan cümlelere kişisel dil (idiolect) birim özelliği katar. Atasözü olan cümlelerde ise cümlede yer alacak sözlerin ve öge diziminin belirlenmesinde, kişisel dil kullanıcısının etkisi yoktur. Söz varlığındaki sözlerin aynı dil kullanıcılarının ortak sözlük birimleri olması gibi atasözleri de aynı dil kullanıcılarının ortak cümleleridir. Bu da atasözü olan cümlelere, toplumsal dil (sociolect) birimi özelliği yükler.

\section{Bir Cümleden Oluşan Kazak Atasözlerindeki Öge Dizimleri}

Çözümlenen tek cümlelik Kazakça atasözleri, sırasıyla cümlenin temel ögelerinden olan yüklemin türü ile çalkalanma durumuna ve öznenin bağımsız dil birimi olarak varlığına göre sınıflandırıldı. Sınıflandırma sonucunda oluşan kümelerdeki atasözlerinin öge dizimleri ve dizi sıklıkları belirlendi. Sınıflandırma ve sınıflandırma sonucunda oluşan kümelerdeki atasözlerinin öge dizimleri ve sıklıkları şöyledir:

\subsection{Yüklemi fiil olan atasözleri}

İncelenen 2726 atasözünden 1881'inde yüklemin fiil olduğu tespit edilmiştir. Bu atasözlerinin öge dizimlerinin yüklemin çalkalanıp çalkalanmamasına ve öznenin eksiltilip eksiltilmemesine göre sınıflandırılması ve dizi sıklıkları şu şekildedir.

2.1.1. Fiil yüklemi çalkalanmamış ve öznesi eksiltilmemiş atasözleri

Fiil yüklemli 1881 cümleden 1330'unda yüklem çalkalanmamış, özne eksiltilmemiş. Bu 1330 atasözü 49 farklı öge dizimiyle kurulmuş. Öge dizimi kalıplarının dizi sıklıklarına göre sıralanması şöyledir:

2.1.1.1. zt/ö/y (195) (dizi sıklığ1): 1763. Üş balanı ösirgenşe, üş şahar apat boladı. 3036. Ot degenmen avız küymes. 3700. Jetimniñ avzı asḳa tiyse, murnı ḳanaydı. 17 (Aynı öge dizimi kümesinden, varsa, üç atasözü örnek olarak verildi ve varsa, öge dizim kümesindeki diğer atasözlerinin Babalar Sözi 65. Tom, Kazak Makal Mételderi adlı kitaptaki sıra numarası yazıld1), 43, 51, 92, 104, 127, 129 (4202) (Aynı atasözünün tekrar edildiği sıra numarası), 197, 244, 269, 279, 295 (4416), 302, 305, 330 (352), 331, 344, 348, 381, 383, 482, 502, 538, 551, 563, 620, 735, 744, 785 (811), 881, 894, 925, 976, 1029, 1065, 1068, 1077, 1109, 1191, 1214, 1245, 1254, 1259, 1261, 1302, 1357, 1422, 1450, 1511, 1609, 1622, 1684, 1691, 1706, 1739, 1747, 1754, 1767, 1798, 1802, 1827, 1855, 1887, 1918, 1967, 2043, 2092, 2095, 2098, 2099, 2199, 2212, 2229, 2235 (2527), 2374, 2420, 2470, 2635, 2651, 2726, 2735, 2740, 2750, 2770, 2800, 2803, 2821, 2851, 2904, 2908, 2973, 3007, 3019, 3034, 3083, 3106, 3114, 3128, 3153, 3164, 3195, 3216, 3238, 3243, 3272, 3313, 3365, 3370, 3455, 3457, 3527, 3686, 3715, 3724, 3800, 3801, 3823, 3842, 3843, 3858, 3950, 3967, 4014, 4019, 4026, 4058, 4063, 4065, 4097, 4146, 4170, 4192, 4196, 4198, 4218, 4314, 4335, 4362, 4392, 4400, 4431, 4437, 4445, 4541, 4638, 4648, 4678, 4796, 4824, 4862, 4875, 4878, 4925, 4931, 5057, 5086, 5091, 5092, 5093, 5103, 5104, 5105, 5122, 5180, 5193, 5277, 5339, 5369, 5396, 5408, 5465, 5467, 5505, 5518, 5531, 5554, 5557, 5604, 5666, 5711, 5743, 5793, 5794, 5800, 5805, 5845, 5851, 5866, 6046, 6067, 3025, 5058.

2.1.1.2. ö/zt/y (187): 1526. J1layın degen bala ékesiniñ sakalımen oynaydı. 3534. Avzı küygen ürip işer. 3926. Bos ḳap tik turmaydı. 24, 28, 49, 203, 233, 260, 322, 337, (2922), 363, 365, 439, 474, 582, 599, 609, 611, 631, 668, 691, 707, 746, 900, 942, 959, 1008, 1086, 1095, 1212 (2117), 1327, 1181, 1358, 1361, 1365, 1408, 1519, 1529, 1605, 1626, 1640, 1670, 1687, 1766, 1778, 1881, 1882, 1935, 1981, 2001, 2056, 2118, 2129, 2357, 2399, 2453, 2538, 2586, 2591, 2648, 2673, 2763, 2783, 2903, 2944, 2953, 2966, 3001, 3038, 3199, 3245, 3250, 3378, 3412, 3414, 3420, 3517, 3538, 3585, 3601, 3625, 3627, 3629, 3667, 3670, 3698, 3704, 3718, 3806, 3869, 3881, 3888, 3947, 3972, 3996, 4035, 4047, 4066, 4118, 4123, 4182, 4186, 4276, 
4289, 4355, 4379, 4380, 4396, 4421, 4476, 4524, 4582, 4597, 4617, 4622, 4705, 4717, 4747, 4751, 4789, 4804, 4811, 4838, 4892, 4943, 4961, 4981, 4988, 5011, 5050, 5051, 5052, 5056, 5168, 5181, 5194, 5234, 5299, 5305, 5314, 5350, 5355, 5357, 5365, 5384, 5387, 5389, 5391, 5440, 5461, 5477, 5671, 5677, 5680, 5701, 5702, 5719, 5732, 5745, 5758, 5761, 5775, 5801, 5807, 5823, 5827, 5859, 5871, 5872, 5893, 5895, 5896, 5950, 5954, 5978, 5984, 5986, 6020, 6072, 3280.

Beş cümlede zarf tümleci, özne olan belirtili ad tamlamasının içine, tamlayan ve tamlanan unsur arasına çalkalanmış: 1525. Jllaytuġın balanıñ /üş kün burın/ közi ḳışıydı. 2887. Jasında şapalak jegenniñ /öskende/ ökinişi az boladı. 2888. Jayavdıñ /attığa ilesemin dep/ tañ jırtılıptı. 5729, 5796.

Bir cümlede zarf tümleci ve yüklem, özne olan belirtili isim tamlamasının içine çalkalanmış. 2846. Erte turgan koyşınıñ /egiz ḳozdar/ koyları.

2.1.1.3. ö/yt/y (178): 1241. Adam bolatın bala alısḳa ḳaraydı. 2662. Aydıñ jarıġı özine tüspeydi. 2900. Jırtık tesikke küledi. 73, 218, 357, 360, 463, 472, 509, 531, 558, 607, 640, 676, 702, 705, 752 (2939), 779, 782, 963, 1019, 1028, 1062, 1146, 1166, 1196, 1462, 1486, 1697, 1710, 1716, 1791, 1793, 1807, 1819, 1831 (2759), 1844, 1862, 1875, 1904, 1927, 1947, 1948, 1949, 2009, 2020, 2023, 2061, 2093, 2131 (3882), 2302, 2406, 2623, 2670, 2744, 2809, 2865, 2880, 2920, 2947, 2984, 3014.1, 3053, 3067, 3115, 3118, 3129, 3139, 3205 (4090), 3258, 3359, 3382, 3399, 3423, 3466, 3496, 3545, 3573, 3646, 3651, 3668, 3711, 3727, 3728, 3729, 3857, 3884, 3893, 3894, 3903, 3912, 3922, 3925, 3932, 4009, 4021, 4087, 4089, 4094, 4119, 4228, 4269, 4272, 4305, 4330, 4412, 4467, 4484, 4537, 4598, 4610, 4613, 4681, 4694, 4695, 4714, 4806, 4808, 4911, 4914, 4977, 4978, 4986, 5004, 5005, 5142, 5157, 5171, 5216, 5226, 5254, 5285, 5291, 5358, 5363, 5372, 5405, 5412, 5418, 5483, 5520, 5528, 5529, 5532, 5533, 5549, 5559, 5582, 5615, 5616, 5649, 5663, 5668, 5700, 5763, 5767, 5769, 5787, 5790, 5792, 5798, 5808, 5854, 5878, 5891, 5910, 5919, 5922, 5951, 5961, 5990, 6006, 6015, 6030, 6060.

İki cümlede yer tümleci, özne olan belirtili ad tamlamasının içine, tamlayan ve tamlanan unsur arasına çalkalanmış: 4247. Dostıñ /dosḳa/ zalalı bolmas. 5424. Atı joktıñ /avildasḳa/ akısı ketpeydi.

2.1.1.4. ö/y (142): 2030. Özi kulag̉an j1lamas. 2544. Keñesip kesken barmak avırmaydı. 5949. Ölgen s1yır sütti bolad1. 59, 77, 121, 164, 195, 257, 273, 301 (3677, 5741), 315, 342, 366, 373, 435, 495, 540, 541, 617, 621 (4154), 747 (4402), 763, 907, 1036, 1055, 1079, 1093, 1103, 1112, 1133, 1137, 1296, 1568, 1656, 1665, 1700 (3066), 1727, 1779, 1851, 1905, 1956, 1989, 1995 (3803), 1999, 2012, 2028 (4521), 2029, 2133, 2190, 2345, 2352, 2380, 2422, 2543, 2589, 2630, 2687, 2795, 2845 (2917), 2847 (2918), 2916, 2924, 2975, 2981 (3717), 3035, 3045, 3050, 3088, 3103, 3126, 3194, 3235, 3297, 3327, 3396, 3415, 3418, 3558, 3591, 3664, 3682, 3697, 3702, 3755, 3756, 3861 (6017), 3885, 3997, 4095, 4193, 4310, 4336, 4395, 4427, 4428, 4523, 4583, 4715, 4720, 4721, 4760, 4812, 4836, 4841, 4842, 4855, 4941, 4942, 4994, 4999, 5003, 5097, 5121, 5141, 5214, 5227, 5241, 5252, 5273, 5276, 5354, 5371, 5399, 5414, 5430, 5432, 5493, 5508, 5536, 5583, 5587, 5716, 5795, 5809, 5831, 5934, 5937, 5952, 5959, 6049, 6063.

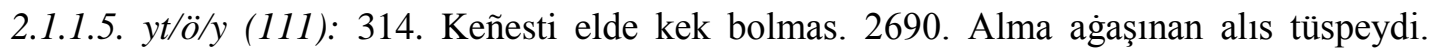
3986. İyne ötken jerden jip te ötedi. 108, 283, 288 (2891), 332, 361, 362, 364, 406, 408, 695, 750, 753, 895, 941, 1082, 1158, 1226, 1237, 1373, 1389, 1497, 1536, 1585, 1621, 1676, 1719, 1737, 1777, 1834, 1852, 1903, 1919, 1930, 1977, 1993, 2048, 2072, 2079, 2087, 2100, 2139, 2246, 2301, 2313, 2396, 2502, 2691, 2700, 2741, 2767, 2801, 2849, 2883, 2958, 3110, 3247, 3248, 3273, 3347, 3351, 3471, 3531, 3577, 3623, 3666, 3695, 3938, 3965, 3980, 4078, 4185, 4257, 4385, 4485, 4510, 4520, 4649, 4669, 4677, 4752, 4877, 4932, 4935, 4993, 5042, 5048, 5156, 5255, 5301, 5318, 5362, 5402, 5435, 5566, 5598, 5621, 5692, 5709, 5710, 5731, 5737, 
5825, 5880, 5940, 5941, 5942, 5948, 6027.

2.1.1.6. blin/ö/y (99): 271. Jarlınıñ jalġız ḳozısın ḳasḳır jeydi. 831. Jaḳsınıñ ḳadirin jaḳsı biler. 1374. Babas1 ekkendi balas1 orad1. 1, 118, 138 (4730), 159, 173, 276, 298, 398 (3747), 430, 514, 532, 569, 625, 724, 1034, 1050, 1097, 1106, 1134, 1239, 1338, 1339, 1571, 1708, 1794 (3251), 1916, 1990, 2484, 2688, 2824, 2885, 2983, 2989, 3190, 3362, 3371, 3377, 3427, 3582, 3615, 3696, 3736, 3739, 3969, 4007, 4061, 4159, 1355, 4403, 4405, 4413, 4456, 4517, 4553, 4609, 4650, 4663, 4722, 4794, 4839, 4833, 4979, 4983, 4995, 5008, 5014, 5106, 5164, 5238, 5251, 5317, 5378, 5436, 5517, 5521, 5527, 5612, 5634, 5647, 5688, 5694, 5695, 5706, 5713, 5742, 5791, 5826, 5855, 5888, 5890, 5964, 5965, 6010, 6018, 6024, 6051.

2.1.1.7. ö/blin/y (81):1801. Aḳımaḳ aḳılsızdıg̀ın moyındamaydı. 3606. Bal ḳuygan barmaġın jalar. 5401. Ajaldı tüye jardı attayd1. 148, 289, 290, 461, 476, 503, 517, 736, 748, 909, 916, 1066, 1080, 1167, 1206, 1227, 1294, 1304, 1487, 1517, 1538, 1705, 1707, 1733, 1801, 1902, 2017, 2024, 2038, 2111, 2692, 2713, 2802, 3026, 3206, 3324, 3487, 3586, 3606, 3772, 3785, 3826, 3987, 4017, 4099, 4137, 4147, 4149, 4174, 4216, 4235, 4367, 4430, 4608, 4630, 4672, 4455, 4723, 4777, 4969, 4970, 4974, 5070, 5132, 5152, 5185, 5203, 5401, 5486, 5656, 5674, 5703, 5749, 5760, 5768, 5868, 5918, 5920, 5960, 5998, 6066.

2.1.1.8. ö/bsizn/y (63): 1180. (4052) Ötpes pışak kol keser. 5182. Kişkene tas bas jarar. 6061. Üregen iyt kisi kappas. 242, 1180 (4052), 1211(2113), 1274, 1440, 1582, 1657, 1686, 1828, 1832, 1953, 2138, 2184, 2442, 2507, 2592, 2636, 2686, 2746, 2747, 2869, 2890, 2954, 2972, 2996, 3040, 3062, 3101, 3366, 3468, 3514, 3535, 3662, 3745 (3751), 3892, 3984, 4008, 4018, 4039, 4210, 4234, 4659, 4688, 4734, 4795, 4810, 5088, 5147, 5162, 5182, 5186, 5208, 5257, 5331, 5332, 5364, 5628, 5717, 5786, 5803, 5836, 5894, 6061

2.1.1.9. zt/yt/ö/y (28): 36. Aspannan kiyiz javsa da, kulga ultarak tiymeydi. 1295. Ataña ne kı1lsañ, aldıña sol keler. 3721. Kazanġa ne salsañ, şömiş̧iñe sol iliner; 44, 561, 832, 990, 1284 , 1534, 1627, 1994, 2465, 2771, 3008, 3152, 3203, 3233, 3536, 3710, 4387, 4473, 4557, 4593, 4718, 5584, 5869, 5892, 6012.

2.1.1.10. ö/zt/yt/y (25): 2428. Aḳımak javındı küni suvga tüser. 2862. Jazdı küni jılannan korıkkan, ḳıstı küni ala jipten attamas. 5033. Er jigit üyde tuvıp, tüzde öler. 64 (1344), 997, 1344, 1350, 1428, 1518, 1792, 2701, 2701, 3163, 3722, 4116, 4361, 4513, 5034, 5611, 5697, 5771, 5776, 5995, 6022, 6025

2.1.1.11. zt/ö/yt/y (24): 4114. Ayuvmen joldas bolsañ, aybaltañ janıñda bolsın! 5901. Mal malg̀a jetkenşe, gazırayıl janġa jeter. 5931. Mal kökke toymay, avzıñ aḳka tiymeydi; 139, 186, 1630, 1923, 2665, 2676, 2945, 2991, 3003, 3006, 3289, 3307.1, 3578, 5515, 3900, 3959, 4004, 4013, 4301, 4865, 5750.

2.1.1.12. ö/zt/blin/y (23): 75. Bay kedeylense de, maḳtanġanın ḳoymas. 3411. Ötirikşi aldımen özin aldar. 5428. At semirse, iyesin teber. 216, 728, 923, 1233, 1369, 1478, 1841, 1979, 2069, 3024, 3766, 3777, 3804, 4365, 5594, 5778, 5779, 5782, 5783, 6052.

2.1.1.13. zt/ö/zt/y (20): 2863. Jaz kiyimin ḳıs kiyip, jarlı ḳaydan bayısın. 4944. Eñbeksizge aspan ast1 tar keler. 3595. Aşarş1lı̣ta ḳomagaay burın öledi. 412, 616, 1654, 1746, 2115, 2197 , 2198, 2523, 3204, 5109, 5197, 5534, 5542, 5844, 5857, 5858, 6023.

2.1.1.14. zt/ö/blin/y (17): 601. Aḳıldı oylanġanşa, tentek isin bitirer. 2668. Arasında murın bolmasa, eki köz birin-biri şuḳır edi. 4439. Köp uyġarsa, han tüyesin soyadı| 544, 809, 1121, 1326, 1459, 1773, 2667, 2858, 4190, 4237, 4584, 5027, 5328, 5881.

2.1.1.15. ö/zt/bsizn/y (15): 690. Bürkit ḳartaysa, tışḳan avlayd1. 2758. Érkim öz boyına ḳarap ton pişer. 1151. Koyşınıñ ḳızı ḳoy kelgende is tiger. 1168, 1608, 1637, 2444, 3014, 3151, 3368, 3638, 4647, 5271, 5708, 5753.

2.1.1.16. ö/yt/bsizn/y (15): 2300. Kudıḳtan suv işken ḳazganġa raḳmet aytadı. 3979. Jaña 
kiyim jat jerde tamak éperedi. 6055. Üre bilmegen iyt üyine ḳonaḳ keltiredi; 68, 147, 1940, 2010, 2016, 2460, 2519, 2612, 2780, 3054, 3880, 4922.

2.1.1.17. zt/ö/bsizn/y (13): 428. Kuttı ḳonaḳ kelse, ḳoy egiz tabadı. 1465. Eñbekşi ḳatınnıñ kolı jip iyirse, ayag்ı besik terbetedi. 175. El arası javıkssa, epti jigit ḳalıñsız ḳatın aladı; 930, 1632, 1786, 2805, 3789, 3924, 4229, 5816, 5975, 6011

2.1.1.18. ö/blin/zt/y (13): 2703. At baspaymın degen jerin üş basad1. 5757. İyt balasın irıldap süyedi. 3896. Istık sütten avzı küygen ayrandı ürlep işedi. 1192, 2083, 2672, 2760, 3587, 3621, 4614, 5522, 5545, 5936.

2.1.1.19. ö/zt/zt/y (11): 3768. Konak az otırıp, köp sinaydı. 5600. Esek bargaa sanalsa da, malġa sanalmayd1. 1879. Eki tentek kezdesse, töbelespey tarḳamaydı. 1561, 1624, 1880, 3551, 4038, 4544, 5759, 5873.

2.1.1.20. zt/zt/ö/y (7): 1920. Kisiniñ közine köziñ tüsse, köñili jibip, meyiri tüser. 4328. Jazım bolsa, bılamıḳa tis sınar. 5560. Bıyıl izi bolsa, keler j11ı özi bolar. 1685, 3913, 5085, 5874.

2.1.1.21. ö/yt/zt/y (7): 223. Eşkim anadan ḳul bolıp tuvmaydı. 1532. Jatıp işer jalḳav ḳatın sormañday erge tus keler. 5202. Karag̉ay da öz jerinde dürildep janadı. 1371, 2130, 5049.

Bir cümlede yer tümleci, özne olan belirtili ad tamlamasının içine tamlayan ve tamlanan unsur arasına çalkalanmış: 1868. Eki sarañnıñ /bir-birine/ kolı ézer jetedi.

2.1.1.22. blin/ö/zt/y (7): 612. Alla jaḳkan şıraḳtı, aḳımaḳ ürlep söndirmes. 1945. Kisiniñ joġın kisi öleñ aytıp jürip ḳaraydı. 2860. Eminip alġan bayımdı, eşki tevip öltirdi; 693, 3138, 5395, 6053.

2.1.1.23. ö/blin/yt/y (5): 246. Jaman körşi sırıñdı sırtḳa jayadı. 3460. Söyley bilmegen jaman sözdi özine keltirer. 5752. İyt aşuvın mısıktan aladı. 4764, 5442.

2.1.1.24. zt/blin/ö/y (4): 193. Eliñdi dav bassa, üyiñdi ḳarız basadı. 2348. Ortaşa bolsañ, aḳıñdı eşkim jemeydi. 5107. Jaḳsı bolsa javjumırdı iyt jemey me? 5797.

2.1.1.25. blin/yt/ö/y (4): 679. Bitisi jaman ḳamıstı, suv işinen ört şaladı. 680. Tuvısı jaman jigitti tüye üstinen iyt ḳabad1. 957. Jürisi jaman jigitti el işinde jav alar. 4863.

2.1.1.26. $y t / y t / o ̈ / y ~(3): 533$. Üyde tuvısı köpke tüzde duşpanı tiymeydi. 1413. Balaga torgaydıñ köleñkesinen suvı̣ tiyedi. 3971. Jolı bolar jigitke joldan joldas ḳosılar.

2.1.1.27. yt/ö/bsizn/y (3): 4870. Bir kisi ḳazganan arıḳtan mıñ kisi suv işedi. 2969. Küriş arḳasında kürmek suv işipti. (5167) 5947. Ötkelde tüyeniñ ülkeni tayak jeydi.

2.1.1.28. ö/zt/yt/bsizn/y (3): 922. Jaman özi tüyeniñ üstinde kele jatıp, jayavġa «buk»» deydi. 1193. Soḳırdı ḳaravıl ḳoysañ, üstiñe jav keltirer. 3169. Tışḳan inine kire almay jürip, kuyrıġına kalbır baylaptı.

2.1.1.29. ö/yt/blin/y (3): 2071. Sarañ iytten sorpasın da ḳıġanad1. 4563. Suvdan tonın ayamaġan, javdan janın ayamas. 5329. Tavġa süyengen er, tavday javdı jıġadı.

2.1.1.30. ö/ö/y (3): 780. Jaḳsınıñ şarapatı, jamannıñ kesapatı tiyer. 2886. Jañılmas jaḳ, sürinbes tuyak bolmas. 3229. Aytḳan söz, atḳan oḳ ḳaytpaydı.

2.1.1.31. zt/ö/zt/bsizn/y (2): 2837. Dariya jolı suv bolsa da, iyt tilimen suv işer. 6074. İs oñına basarda, şıbış laḳtap, toḳtı ḳozdaydı.

2.1.1.32. $y t / o ̈ / z t / y$ (2): 2185. Asıġistak pen aşuvdan aḳ1l küñgirt tartar. 5325. Temirşiniñ kolında temir erip suv bolar.

2.1.1.33. blin/zt/ö/y (2): 2951. Köñildi kötermese kir basadı. 3255. Avzı ḳulıp sandıktı tic aşpasa, til aşar.

2.1.1.34. zt/zt/ö/bsizn/y (1): 3491. Tildiñ mayın tamızıp, sözdiñ balın aġızıp, ķas şeşender söz aytar.

2.1.1.35. yt/zt/ö/y (1): 4205. Bir kün urısḳan üyde ḳırıḳ kün bereke bolmaydı.

2.1.1.36. yt/blin/ö/y (1): 94. Baydıñ mıñınıñ işinde jarlınıñ jalġız toḳtısın ḳasḳır jeydi. 
2.1.1.37. $\ddot{o} / y t / y t / y$ (1): 5516. Akssak iyt cay iytten savga tileydi.

2.1.1.38. $y t / 0 \ddot{y} /$ t/y (1): 407. Karaşa üyde suñḳar bar orazdig̀a kezdeser.

2.1.1.39. ö/yt/zt/bsizn/y (1): 3159. Tışḳan ininde şalḳasınan jatıp, «aspandı ayağımen tirep jatırmın» deydi.

2.1.1.40. zt/yt/ö/bsizn/y (1): 5875. Ḳırda ḳırı̣ ḳoy suv işse, oyda otız ḳoy nér aladı.

2.1.1.41. zt/ö/blin/zt/y (1): 4267. Duşpan ḳumırsḳa bolsa da, sen onı pildey kör.

2.1.1.42. $\mathrm{zt} / 0 \ddot{/ z t} / \mathrm{blin} / y$ (1): 6007 . Tulpardı altın tagamen tagalasa, esek emeksip ayaġın köteredi.

2.1.1.43. ö/zt/yt/zt/y (1): 3879. Tokşıll1ḳta jegen toḳpan jilik, aşarş1lıḳta köziñnen bir-bir uşar.

2.1.1.44. zt/ö/zt/yt/y (1): 2870. Jalşınıñ malın jasañga aydasañ, ḳuday ḳuvalap ḳuvañğa şıgaradı.

2.1.1.45. ö/blin/ö/y (1): 2761. Érkim teñin özi oljalaydı.

2.1.1.46. zt/ö/yt/blin/y (1): 1507. Jalg̀ız balası atḳa şapsa, anası üyinde taḳımın ḳısadı.

2.1.1.47. $\ddot{o} / z t / z t / z t / y$ (1): 5514. Av1l iyti ala bolsa da, böri körgende birigip ketedi.

2.1.1.48. ö/zt/blin/zt/blin/ztly (1):1425. Bay kündiz béybişesin, Tünde toḳalın jaḳsı köredi.

2.1.1.49 ö/ö/zt/yt/y (1): 5076. El küygende, küyingen batır, el süyingende, süyingen batır, eregiste mıñga tatır.

2.1.2. Fiil yüklemi çalkalanmamış ve öznesi eksiltilmiş atasözleri

Fiil yüklemli 1881 cümleden 508'inde yüklem çalkalanmamış, özne eksiltilmiş. Bu 508 atasözü, 31 farklı öge dizimi kalıbıyla kurulmuş. Öge dizimi kalıplarının dizi sıklıklarına göre sıralanması şöyledir:

2.1.2.1. zt/y (81): 2275. Körpeñe karay kösil. 3161. Tavga ḳarap tav bolmassiñ. 5603. Esektiñ jügi jeñil bolsa, jataġan boladi; 12, 33, 53, 124, 145, 160, 264, 268, 272, 282, 470, 498 (1714, 3082, 4542), 594, 904, 933, 1153, 1324, 1615, 1744, 1810, 1847, 1933, 1957, 2146, 2170, 2192, 2193, 2203, 2207, 2213, 2228, 2234, 2254, 2281, 2283, 2361 (3173), 2377, 2436, 2481, 2546, 2590, 2615, 2634, 2835, 2907, 2928 (4440), 2952, 3075, 3102.1, 3134, 3141, 3699, 3769, 3844, 3872, 3994, 4044, 4045, 4187, 4231, 4261, 4298, 4349, 4420, 4470, 4511, 4566, 4736, 4762, 4887, 4959 (5213), 5163, 5204, 5229, 5237, 5625, 5718, 5861.

2.1.2.2. zt/yt/y (69): 2353. Törde orın barda, tömenge otırma. 3464. Suray-suray, mekkege de jetesiñ. 3676. Zamandasiñ bolmasa toyġa barma. 39, 65, 149, 359, 388, 389, 402, 477, 559, 947, 949, 981, 1288, 1736, 1762, 1842, 1886, 1924, 1936, 1944, 2206, 2013, 2015, 2025, 2154, 2173 (3901, 4825), 2253, 2515, 2816, 2841 (167, 2914), 2852, 2855, 2941 (3999), 3012, 3058, 3294, 3417, 3493, 3500 (4664), 3522, 3553, 3796, 3889, 3905, 4107, 4158, 4225, 4285, 4295, 4343, 4358, 4366, 4611, 4652, 4671, 5211, 5248, 5462, 5502, 5578, 5590, 5722, 5725, 6033, 6037, 6076.

2.1.2.3. zt/zt/y (65): 1164. Oñ ḳolıñ ḳ1lış köterse, sol ḳolıñmen bas. 2150. Az söylep, köp tıñda. 2355. Tünde tırnaġıñ sınsa, tañ atḳanşa jelimdep ḳoy; 7, 30, 234, 486 (3818), 732, 931, 973, 938, 967, 1246, 1265, 1725, 1774, 1939 (2557), 2004 (3394, 4509), 2073, 2176, 2244, 2259, 2287, 2337, 2344, 2571, 2730, 2749, 2881, 3148, 3284, 3296, 3742, 3824, 3891, 3915, 4028, 4053, 4056, 4112, 4258, 4317, 4406, 4474, 4492, 4493, 4540, 4691, 4731, 4740, 4768, 4829, 4948, 5024, 5148, 5172, 5262, 5321, 5398, 5417, 5468, 5561, 5691, 5788, 6009.

2.1.2.4. zt/blin/y (64): 1846. Basıñ aman bolsın deseñ, tiliñdi toktat. 3953. Jaz boldı dep, ḳ1s tonıñdı tastama. 3781. Konaḳta öz üyiñdi oylap otır. 248, 345, 353, 452, 525, 1171, 1520, 1825 (3257), 2036, 2167, 2172, 2215, 2257, 2269, 2271, 2272, 2351 (4083), 2358, 2362, 2363, 2930, 2936, 3009, 3052, 3061, 3076, 3162, 3295, 3328, 3442, 3525, 3783. 1, 3787, 3829, 3895, 3931, 3968, 4175, 4213, 4359, 4363, 4386, 4415, 4435, 4438, 4444, 4471, 4743, 4826, 4852, 5192, 5201, 5250, 5562, 5591, 5730, 5735, 5799, 5810, 5967, 6041.

2.1.2.5. yt/bsizn/y (34): 177. El avzına ḳaḳpaḳ ḳoya almaysiñ. 4050. Ok jetpes jerge ḳ1lış silteme. 4767. İYtten süyek ḳarıdar; 134, 230, 356, 519, 615, 1218, 1522 (2892), 1937, 2153, 
2216 (3934), 2245, 2265, 2318, 2331, 2472, 2637, 2706, 2743, 2836, 2889, 3069, 3815, 4189, 4194, 4249, 4809, 4913, 5346, 5245, 5259, 5983.

2.1.2.6. zt/bsizn/y (34): 489. Patşa bolsam, may jer edim. 2456. Aşuviñ kelse, kolıñ tart. 4551. Siylasañ, s1y körersiñ ; 18, 287, 570, 788, 896, 1213, 1566, 1613, 1885, 2705, 2177 (3526), 2214 (3940), 2286, 2564, 2621, 2638, 2693, 2733, 2842, 3133, 3147, 3395, 3613, 3958, 4255, 4375, 4653, 4924, 4947, 5585, 6014.

2.1.2.7. blin/zt/y (33): 2292. Kasıktap jıynagandı şömiştep tökpe. 3779. Konaḳtı sözben toyġiza almaysiñ. 5739. İytti küşiginde üyret; 281, 520, 632, 1156, 2085, 2196, 2285, 2295, 2342, 2343 (5322), 2774, 2813, 2926, 2979, 3530, 3642, 3701, 3743, 3836, 3867, 4496, 4710, 5206, 5455, 5829, 2458, 4497, 5661, 5740, 6044.

2.1.2.8. yt/y (29): 1170. Opasızdıñ otına j1lınba. 3669. Jatık üyinde jatık bol. 5286. Suvın işken kudıḳka tükirme; 133, 293, 306, 427, 1221 (2356), 1674 (3002), 1934, 2297 (2976), 2303, 2317, 2322, 2330 (3828), 2333 (4559, 5988), 2334, 2678, 2721, 3566, 3974, 4580, 4701, 4733, 5013, 5381, 5552, 5887, 5897.

2.1.2.9. blin/yt/y (16): 789. Jaḳsını joldasınan tanıydı. 4371. Javıñnan jasırgaanıñdı dosıña da aytpa. 5060. Erdi kebenek işinde tan1; 382, 1308, 1671, 1751, 2171, 2267, 2298, 2307, 3085, 3547, 4526, 4556, 5510.

2.1.2.10. blin/y (14): 479. Özi jarımaġannıñ sarḳıtın işpe. 2319. Özi bolġan jigittiñ atasın surama. 2815. Beli avırmastı̃ nan jesin ḳara. 1174, 1240, 2464, 3771, 4867, 4077, 4278, 4357, 4547, 4596, 5943.

2.1.2.11. zt/yt/bsizn/y (8): 553. Han ḳasında uvézir bilgiş bolsa, ḳara jerden keme jürgizedi. 597. Ayırılmastay dosıña kayırılmastay söz aytpa. 2282. Kadiriñdi sınayın deseñ, dosıñnan jer sura. 651, 1695, 3122, 4612, 5020.

2.1.2.12. zt/zt/bsizn/y (8): 2201. Birevge ölim tilegenşe, öziñe ömir tile. 2156. Aḳımaḳpen toyġa barġanşa, aḳıldımen birge tas tası. 5118. Jılay-jılay arık ḳazsañ, küle-küle suv işersiñ; 2962, 328, 3416, 4133, 5746.

2.1.2.13. yt/zt/y (7): 426. Kuv1s üyden ḳur ş1kpa. 2354. Tüzüv jolda ḳıysık jürme. 3168. Toyġan jerge tog்ı kel; 2320, 3404, 3871, 1968 (5235).

2.1.2.14. zt/blin/yt/y (6): 2218 (3927). Biytke ökpelep, tonıñdı otḳa salma. 5879. Koydı jel uşırsa, eşkini aspanda körersiñ. 4222. Basıñdı davġa berseñ de, joldasıñdı javġa berme; 2878 (3981), 3639, 6035.

2.1.2.15. zt/blin/zt/y (6): 971. Jamannıñ aldına as ḳoysañ, eki ḳolın birdey saladı. 2022. Öziñdi er dep bilseñ, duşpanıñdı şer dep bil. 2909. Zamanı ḳalay bolsa, börikti solay kiy; 3030, 5498, 5889.

2.1.2.16. $y t / b l i n / y$ (5): 2219. Ġalım aldında avzıñdı tıy. 2438. Arzımasḳa aḳılıñdı tavıspa. 3847. Toyda tonıñdı surama. 1711, 2753.

2.1.2.17. zt/zt/blin/y (4): 42. Atañnıñ kulı aytsa da, édildikke bası̃ndı iy. 1740. Uyada ne körseñ, uşḳanda sonı ilersiñ. 4869. Bir j1l jemis ekseñ, jüz j1l mévesin jeysiñ. 3179.

2.1.2.18. zt/zt/zt/y (4) 2359 (4619). Urıp-urıp oymen jürgenşe, urg்ızıp-urġızıp ḳırmen jür. 3564. Ac işip avırgaanşa, aş bolıp sav jür. 4469. Kolıñnan bir kelse, javġa eki ḳ1l. 3807.

2.1.2.19. bsizn/y (3): 2993. Kuldıñ ḳalaġan asın kim dayındap berer deysiñ. 3786. Konak közinşe iytiñe de ket deme. 4554. «saḳtansañ, saḳtarmın» depti.

2.1.2.20. $y t / y t / y$ (3): 1234. Şarasızdan şalga ketip baramın. 3678. Kelgenniñ mandayınan, ketkenniñ jelkesinen sıypa. 3849. Toydan ḳınıña jak.

2.1.2.21. zt/yt/zt/y (3): 2288. Karañg்ıda ḳırık kün ḳaltıraġanşa, jarıḳta bir kün jaltıra. 3167. Tüse almasiñdı bilgen soñ, tüyege nege minesiñ. 4110. Aldıña bir ḳarasañ, artıña eki ḳara.

2.1.2.22. yt/zt/bsizn/y (2): 141 (3619). Bir kün ḳarnı aşḳannan ḳırıḳ kün aḳıl surama. 4002. 
Köñilsiz erge ḳaruv bergenşe, kösev ber.

2.1.2.23. blin/zt/blin/zt/y (2): 4816. Ag̉aştı japıraġına ḳarap, Adamdı isine ḳarap tanıydı. 978. Jamandı isinen, Aḳılsızdı sözinen tanı.

2.1.2.24. blin/zt/zt/y (1): 4143. Avı1 üydiñ monşaġın kündiz urlap, tünde tak.

2.1.2.25. blin/yt/ztty (1): 2729. «Atand1 alatavda bir j1g்ı em».

2.1.2.26. zt/yt/blin/y (1): 946. Jamannan ḳarız alsañ, tar jerde janıñdı alar.

2.1.2.27. $y t / z t / z t / y$ (1): 3776. Konaḳka surap bergenşe, urıp ber.

2.1.2.28. zt/zt/yt/y (1): 940. Jamanmen janatta bolġanşa, jakssımen tozaḳta bol.

2.1.2.29. Zt/blin/zt/blin/y (1): 2684. Aḳ1lmen mıñdı, aḳıruvmen birdi köndiresiñ.

2.1.2.30. blin/yt/blin/yt/y (1):568. Abıroydı tüzden, nesibeni üyden ber.

2.1.2.31. zt/zt/zt/yt/y (1): 3498. Tüstik jerge ötirik aytsa, keşke iziñmen artıñnan baradı.

2.1.3. Fiil yüklemi çalkalanmış ve öznesi eksiltilmemiş atasözleri

Fiil yüklemli 1881 cümleden 28 'inde yüklem çalkalanmış, özne eksiltilmemiş. Bu 28 atasözü, 16 farklı öge dizimi kalıbıyla kurulmuştur. Öge dizim kalıplarının dizi sıklıklarına göre sıralanması şöyledir:

2.1.3.1. zt/ö/y/blin (8): 3529. As ḳadirin bilmeseñ, aşarşılıḳ berer sazañdı. 4346. Jamanġa aytsañ sırıñdı, jaman buzar şırıñdı. 3444. Salalap tarap saḳaldı, kériler aytar maḳaldı. 1484, 1554, 3230, 3650, 5423.

2.1.3.2. ö/y/zt (3): 4023. Kamḳa ton da şüberek bolar tozġan soñ. 4883. Bermeytin nérse bolmayd1, suravı kelisse. 5174. Ken tamırı tabılmas, eñbek etip kazbasa.

2.1.3.3. zt/yt/y/ö (2) 40. Atadan altav tuvsañ da, basıña tüser jalġıdık. 2649. Aġayınnan bölinip ketseñ sayaḳ, tétti etiñe tiyedi aşşı tayaḳ.

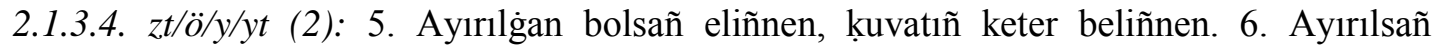
üyiriñnen, kolıñ ketpes büyiriñnen.

2.1.3.5. zt/y/ö (1): 3635. Bılamıḳtı işkende tissiz kéri, elester ötkendegi istiñ béri.

2.1.3.6. yt/y/ö (1): 471. Öz eliñnen şet jerde Şuvakssız bolar köktem de.

2.1.3.7. (uu/uu/)bsizn/y/ö (1):1824. Ayhay, kökirek, Ne demeydi sum jürek!

2.1.3.8. ö/y/blin (1): 142. Bir tévekel jazadı mıñ ḳayġınıñ jarasın.

2.1.3.9. zt/y/ö/zt (1): 4966. Eñbek ḳ1lsañ erinbey, toyadı karnıñ tilenbey.

2.1.3.10. ö/y/yt (1): 1012 (3970). Jolı bolar jigittiñ jeñgesi şığar aldınan.

2.1.3.11. $/$ /blin/y/zt (1): 5595. Esek mingen eñbegin minedi, eki jaḳtap tebine.

2.1.3.12. zt/zt/y/ö (1): 618. Aman bolsa bul basım, tağı şıg̉ar bul şaşım.

2.1.3.13. ö/bsizn/y/yt (1): 1604. Kayın enesi as işpes ḳabag̉ın tüygen kelinnen.

2.1.3.14. ö/ö/y/blin (1): 3859. Tamag்ı toḳtık, jumısı joḳtık, azdırar adam balasın.

2.1.3.15. $\ddot{o} / y t / y / y t ~(1): 4704$. Alıs-beris ḳolınan, şı̇garıp ḳoyar jolınan.

2.1.3.16. zt/zt/bsizn/y/ö (1): 3073. Özi ḳara bolsa da, bak-dévleti say bolsa, jer jaradı kañḳıl1.

2.1.4. Fiil yüklemi çalkalanmış ve öznesi eksiltilmiş atasözleri

Fiil yüklemli 1881 cümleden 15 'inde hem yüklem çalkalanmış hem de özne eksiltilmiş. Bu 15 atasözü 9 farklı öge dizimi kalıbıyla kurulmuştur. Öge dizimi kalıplarının dizi sıklıklarına göre sıralanması şöyledir:

2.1.2.1. blin/y/zt (4): 2468. Boyınıñ uzının ḳayteyin, aḳılı ḳısḳa bolsa. 2776. Barmaḳtay bak ber, tavday talap bergenşe. 3425. Pışagiññ k kayrap jür, ne soyarı̃ bilseñiz. 3330 .

2.1.4.2. zt/y/blin (2): 143. Bir jaḳsıga bitirer kem köñildiñ sapasın. 1197. Siylasañ şalıñdı, jarılkaydı bériñdi.

2.1.4.3. zt/y/yt (1): 656. Aḳ1l alsañ azbassiñ, köpti körgen köneden.

2.1.4.4. $y t / y / z t$ (2): 2360. Ürgen iytke ündeme, öziñdi üstem sanasañ. 3410. Ötiriktiñ özine nanba, akssaḳtı tıñday. 
2.1.4.5. zt/zt/y/yt (2):434. Kuldı jiberseñ erkine, künde tışar börkiñe. 798. Jaḳsıdan jaman tuvsa da, jamannan jakss tuvsa da, tartpay ḳoymas negizge.

2.1.4.6. blin/zt/y/zt (1): 5500. Arık attı tüste bak, ḳarg்ıp tursa ḳanatıñ.

2.1.4.7. zt/blin/y/yt (1): 1912 (4417). Joldas bolsañ ḳuvġa, basiñdı salar davġa.

2.1.4.8. zt/bsizn/y/zt (1): 4433. Körpe salġanġa körpe sal, atañnan ḳalġan ḳul da bolsa.

2.1.4.9. zt/y/zt (1) 4940. Ekseñ egin, işersiñ tegin.

\section{2. İsim yüklemli atasözleri}

Yüklemi isim olan 845 atasözü tespit edilmiştir. Bu atasözlerinin öge dizimlerinin yüklemin çalkalanıp çalkalanmamasına ve öznenin eksiltilip eksiltilmemesine göre sınıflandırılması ve dizi sıklıkları şu şekildedir.

2.2.1. İsim yüklemi çalkalanmamış ve öznesi eksiltilmemiş atasözleri

İsim yüklemli 845 cümleden 824'ünde yüklem çalkalanmamış, özne eksiltilmemiş. Bu 824 atasözü 11 farklı öge dizimi kalıbıyla kurulmuştur. Öge dizimi kalıplarının dizi sıklıklarına göre sıralanması şöyledir:

2.2.1.1. ö/y (513): 2714. Asığıs artı - ökiniş. 3237. Atalar sözi - aḳıldıñ közi. 5110. Jemisti ag̉aştıñ bası tömen. 6056. Ündemegen iyt ḳabaġan. 15, 21, 54, 56, 85, 90, 154, 155, 161, 165 , 176, 183, 185, 200, 207 (2839), 214 (5075), 237, 247, 270, 310, 313, 317, 318, 341, 343, 346, 347, 355, 358, 367, 368, 369, 372, 378, 380, 445, 466, 468, 478, 494, 507, 513, 526, 530, 539, 542, 543, 546, 565, 574, 584, 589, 591, 592, 623, 627, 641, 655, 659, 662, 675, 684, 686, 698, 723, 727, 731 (1510), 764, 793, 862, 875, 884, 888, 915, 932, 944, 992, 1014, 1026, 1044, 1048 (1946), 1052, 1072, 1091, 1100, 1104, 1105, 1108, 1116, 1119, 1122, 1126, 1127, 1136, 1140, 1141, 1203, 1207, 1210, 1219, 1235, 1242, 1249, 1273, 1275, 1286, 1312, 1319, 1328, 1335 , 1346, 1348, 1349, 1352, 1353, 1360, 1367, 1382, 1384, 1387, 1395, 1412, 1417, 1433, 1446, 1456, 1474, 1481, 1495, 1516, 1523, 1544, 1552, 1575, 1581, 1584, 1586, 1598, 1599, 1653, 1659, 1666, 1689, 1728, 1729, 1735, 1752, 1784 (2697), 1795, 1803, 1805, 1808, 1815, 1839, 1860, 1864, 1866, 1872, 1873, 1877, 1895, 1921, 1938, 1950, 1955, 1958, 1960, 1966, 1975, 1982, 1983, 1991, 2005, 2027, 2040 (3409), 2041, 2057, 2067, 2088, 2089, 2090, 2105, 2108, 2126, 2128, 2147, 2157, 2158, 2159, 2164, 2291, 2378, 2410, 2411, 2427, 2449, 2452, 2475, 2489, 2503, 2524, 2526, 2531, 2555, 2560, 2561, 2569, 2581 (2608), 2609, 2616, 2626, 2631, 2652, 2653, 2657, 2658, 2661, 2675, 2681, 2683, 2695, 2748, 2752, 2754, 2757, 2762, 2772, 2781, 2782, 2786, 2798, 2811, 2840, 2853, 2854, 2866 (3303, 3311), 2875, 2877, 2902, 2910, 2925, 2931, 2938, 2955, 2961, 2971, 2985, 2986, 2988, 3021, 3028, 3044, 3051, 3063, 3078, 3080, 3099, 3105, 3108, 3123, 3124, 3125, 3131, 3137, 3143, 3157, 3171, 3191, 3193, 3221, 3222, 3269, 3277, 3291, 3300, 3308, 3344, 3361, 3385, 3387, 3388, 3389, 3393, 3403, 3406, 3424, 3426, 3451, 3467, 3472, 3473, 3485.1, 3492, 3499, 3506, 3507, 3541, 3550, 3560, 3561, 3565, 3581, 3589, 3598, 3616, 3617, 3684, 3689 (5679), 3690, 3693, 3694, 3719, 3720, 3722.1, 3738, 3741, 3746, 3754, 3784, 3788, 3790, 3797, 3805, 3811, 3821, 3827, 3840, 3854, 3855, 3860, 3863, 3868, 3918, 3928, 3929, 3930, 3942, 3944, 3951, 3966, 3975, 3983, 3985, 4001, 4003, 4011, 4032, 4057, 4059, 4060, 4073, 4076, 4093, 4101, 4105, 4132, 4135, 4156, 4161, 4171, 4179, 4206, 4244, 4245, 4254, 4291, 4296, 4304, 4351, 4373, 4378, 4384, 4409, 4411, 4426, 4432, 4434, 4447 (5183), 4465, 4502, 4507, 4530, 4532, 4548, 4576, 4601, 4616, 4624, 4631, 4633, 4637, 4656, 4661, 4676, 4680, 4682, 4693, 4697, 4703, 4735, 4741, 4742, 4757, 4775, 4778, 4814, 4854, 4856, 4857, 4868, 4871, 4872, 4874, 4876, 4904, 4949, 4951, 4955, 4957, 4958, 4962, 4980, 4982, 4989, 4990, 4996, 5012, 5017, 5035, 5039, 5065, 5066, 5078, 5095, 5125, 5128, 5139, 5143, 5166, 5169, 5175, 5187, 5191, 5205, 5221, 5230, 5233, 5243, 5244, 5263, 5266, 5268, 5269, 5274, 5275, 5279, 5283, 5290, 5292, 5312, 5319, 5333, 5335, 
5338, 5343, 5359, 5368, 5382, 5400, 5419, 5494, 5513, 5526, 5538, 5570, 5573, 5574, 5588, 5635, 5642, 5676, 5678, 5704, 5723, 5727, 5728, 5747, 5751, 5764, 5774, 5822, 5838, 5850, 5898, 5902, 5902.1, 5911, 5921, 5939, 5968, 5970, 5971, 5987, 5993, 6028, 6045.

2.2.1.2. yt/ö/y (136): 485. Ölgen sarttıñ ḳoynında nanı bar. 1772. Azġan janġa jın joldas. 2663. Aydiñ da betinde sekpil bar. 2, 26, 122, 227, 256, 308, 376, 401, 411, 433, 447, 454, 458, 460, 462, 488, 508, 535, 554, 556 (3196), 626 (2725), 628, 634, 711, 745, 899, 943, 945, 962, $968,1002,1021,1071,1094,1107,1176,1185,1186,1217,1317,1325,1432,1460,1473$, 1533, 1593, 1603, 1619, 1658, 1704, 1799, 1800, 1806, 1867, 1889, 1892, 1901, 1925 (2960), 2039, 2127, 2642, 2674, 2679, 2725, 2732, 2736, 2775, 2787, 2791, 2830, 2937, 3000, 3029, 3307, 3314, 3373, 3384, 3413, 3441, 3453.1, 3461, 3481, 3501, 3649, 3657, 3661, 3672, 3716, 3737, 3775, 3886, 3957, 3962, 3963, 3995, 4079, 4148, 4152, 4153, 4207, 4226, 4252, 4288, 4382, 4488, 4504, 4514, 4539, 4562, 4572, 4585, 4592, 4603, 4711, 4771, 4776, 4780, 4792, 4801, 4805, 4950, 5010, 5079, 5189, 5217, 5267, 5392, 5404, 5738, 5837, 5958, 5991, 6019.

2.2.1.3. zt/ö/y (89): 1041. Körüvşi joḳta, estüvşi küvé. 2534. Jigitke jetpis öner az. 5885 . Koyġa özinen basḳanıñ béri jav. 190, 198 (4321), 350, 371, 377, 608, 622, 935 (3326, 4342), 987, 1005, 1069, 1172, 1287, 1347, 1366, 1399, 1528, 1698, 1761, 1856, 1857, 1961, 2125, 2151, 2162, 2194, 2335, 2412, 2487, 2488, 2509 (4166), 2532, 2627, 2921 (3993), 2929, 2965, 3015, 3068, 3119, 3275, 3369, 3488, 3528, 3574, 3607, 3641, 3653, 3709, 3712, 3794, 3853, 3935, 4166, 4253, 4302, 4316, 4329, 4333, 4364, 4451, 4459, 4464, 4468, 4491, 4518, 4628, 4679, 4687, 4758, 5009, 5127, 5196, 5218, 5270, 5281, 5324, 5413, 5535, 5550, 5687, 5596, 5726, 5841, 5899, 6050, 6068.

2.2.1.4. ö/zt/y (40): 910. Jaman jigit jasında da şal. 3039. Orındı söz jürekke kuvat. 5006. Er el üşin kuurban. 465, 861, 1120, 1208, 1470, 1515, 1602, 2018, 2110, 2376, 2418, 2669, 2699, 2864, 2990, 2995, 3170, 3305, 3486.1, 3759, 3973, 4124, 4667, 4724, 4953, 5126, 5131, 5165, 5326, 5610, 5682, 5773, 5923, 5926, 6002, 6054.

Bir cümlede zarf tümleci, özne olan belirtili ad tamlamasının içine, tamlayan ile tamlanan arasına çalkalanmış: 2677. Altınnıñ /ḳolda barda/ ḳadiri joḳ.

2.2.1.5. ö/yt/y (29): 924. Jaman öz üyine özi ḳonak. 1385. Bolar bala besikte belgili. 5421 . Attıñ sir1 iyesine mélim. 802, 1334, 1407, 1512, 1748, 2031, 2034, 2391, 2528, 2573, 2584, 2610, 2777, 2911, 3215, 3588, 4140, 4145, 4177, 4178, 4632, 5153, 5609, 5698.

Yer tümleci, iki cümlede özne olan belirtili ad tamlamasının içine, tamlayan ile tamlanan arasına çalkalanmış: 3887. Üyde ası joḳtıñ, /tüzde/ dosı joḳ. 4675. Şığarıp salmagian joldastıñ /joldasḳa/ sandiğ $ı$ joḳ.

2.2.1.6. zt/yt/ö/y (4): 3817. Öziñde ası̃̃ bolsa, birevde kasiñ bar ma? 4991. Erinşekke büginnen erteñ oñay. 5173. Kedeyge aḳısız savıḳtan, aḳılı jumıs artık. 2797 (4200).

2.2.1.7. ö/ö/y (4): 755. Kiyimniñ jañası, dostıñ eskisi jaḳsı. 3812. Oraza, namaz - toḳtıḳta. 4129. Altı alasim, bes beresim jok. 6047.

2.2.1.8. ö/ö/ö/y (4): 5519. Aḳ iyt, ḳara iyt - béri iyt. 3022. Mal, düniye, baylıḳ - ḳoldıñ kiri. 3041. Oñ ḳolım, sol ḳolım - béri de öz ḳolım. 3883. Uşkan ḳus, jügirgen añ - béri tamaḳ.

2.2.1.9. zt/zt/ö/y (3): 156 (4302). Eki kisi ḳagisssa, bir kisige orın bar. 3655. Etke toysam, sorpaġa iyttigim joḳ. 5802. Kün batsa, ḳoyġa soḳpaḳ köp.

2.2.1.10. $\ddot{0} / z t / y t / y(1): 3645$. Eki bas, eki basḳa jörgemde as.

2.2.1.11. $y t / z t / o ̈ / y ~(1): ~ 4709$. Aḳşa jürgen jerde édildikke de, adaldıḳka da orın joḳ.

2.2.2. İsim yüklemi çalkalanmamış ve öznesi eksiltilmiş atasözleri

İsim yüklemli 845 cümleden 12'sinde yüklem çalkalanmamış, özne eksiltilmiş. Bu 12 atasözü 3 farklı öge dizimi kalıbıyla kurulmuştur. Öge dizimi kalıplarının dizi sıklıklarına göre sıralanması şöyledir: 
2.2.2.1. zt/y (10): 4861. Biyik tavdıñ bası bolmasak ta, bavrayındag்i tasımız. 4155. Atañ da bolsa, bir joldas. 5856. Koy körmesek te, eşkili baydıñ ḳızı edik. 1165(3037), 1400, 2539, 3197 , 3612, 4313, 4297.

2.2.2.2. y (1): 5981. Cay sıyırdıñ bog்1 emes.

2.2.2.3. zt/yt/y (1): 3637. Bir üyde neşev bolsañ da, bir-birine meyman.

2.2.3. İsim yüklemi çalkalanmış ve öznesi eksiltilmemiş atasözleri

İsim yüklemli 845 cümleden 9'unda yüklem çalkalanmış, özne eksiltilmemiş. Bu 9 atasözü 3 farklı öge dizimi kalıbıyla kurulmuştur. Öge dizimi kalıplarının dizi sıklıklarına göre sıralanması şöyledir:

2.2.3.1. ö/y/zt (7): 259. Jarlılık degen jakss eken, jatıp işer as bolsa. 2660. Adasḳannıñ ayıbı joḳ, ḳayta üyirin tapḳan soñ. 4203. Bilerligiñ ḳayda, bilmestikti keşpeseñ? 2794, 2876, 3723 (5215), 534.

2.2.3.2. zt/y/ö (1): 4992. Erinşekke joḳ siltav.

2.2.3.3. $\ddot{o} / y / \ddot{~(1): ~ 3432 . ~ S o ̈ z d i n ̃ ~ k ̣ ı s k ̣ a s ı ~ j a k ̣ s ı, ~ a r k ̣ a n n ı n ̃ ~ u z ı n ı . ~}$

\section{Değerlendirme}

3.1. Yüklemin türü ve çalkalanması ile öznenin bağımsız dil birimi olarak cümlede varlığı bakımından öge dizimi kalıpları

Tek cümleden oluşan 2726 Kazakça atasözünden 1881'inin (\%69) yüklemi fiil, 845'inin (\%31) yüklemi isim türünden söz veya söz öbeğidir. 1881 fiil cümlesinden 1838 'inde $(\% 97,71)$ yüklem cümlenin sonunda; 43'ünde $(\% 2,29)$ ise çalkalanmıştır. 845 isim cümlesinden 836 'sında $(98,93)$ yüklem sonda; 9'unda $(\% 1,07)$ ise çalkalanmıştır. Genel olarak değerlendirildiğinde ise 2726 Kazakça atasözünden 2674'ünde $(\% 98,09)$ yüklem cümlenin sonundadır, çalkalanmamıştır; 52 cümlede $(\% 1,91)$ ise yüklem sonda değildir, yani çalkalanmıştır.

1881 fiil cümlesinden 1357'sinde $(\% 72,14)$ özne bağımsız dil birimi olarak bulunurken, 524'ünde $(\% 27,86)$ yer almamakta; 845 isim cümlesinden 833'ünde $(\% 98,56)$ bağımsız dil birimi olarak bulunurken, 12 'sinde $(\% 1,42)$ bulunmamaktadır. Genel olarak değerlendirildiğinde 2726 cümlenin 2190'ında $(\% 80,34)$ özne bağımsız dil birimi olarak bulunurken, 536'sında $(\% 19,66)$ yer almamaktadır.

$2726(\% 100)$ atasözünden 1330 'u $(48,79)$ öznesi eksiltilmemiş ve fiil yüklemi çalkalanmamış cümle, 508'i $(\% 18,63)$ öznesi eksiltilmiş ve fiil yüklemi çalkalanmamış cümle, 28 'i $(\% 1,03)$ öznesi eksiltilmemiş ve fiil yüklemi çalkalanmış cümle, 15 'i $(\% 0,55)$ öznesi eksiltilmiş ve fiil yüklemi çalkalanmış cümle; 824'ü $(\% 30,23)$ öznesi eksiltilmemiş ve isim yüklemi çalkalanmamış cümle, 12 'si $(\% 0,44)$ öznesi eksiltilmiş ve isim yüklemi çalkalanmamış cümle, 9’u $(\% 0,33)$ öznesi eksiltilmemiş ve isim yüklemi çalkalanmış cümledir.

Fiil yüklemi çalkalanmamış ve öznesi eksiltilmemiş 1330 atasözü, 49 farklı öge dizimi kalıbıyla kurulmuş. Dizi sıklıklarına göre, bu atasözlerinin öge dizim kalıpları sırasıyla şunlardır: 195'i zt/ö/y, 186'sı ö/zt/y, 178'i ö/yt/y, 142'si ö/y, 111'i yt/ö/y, 99'u blin/ö/y, 81'i ö/blin/y, 63'ü ö/bsizn/y, 28’i zt/yt/ö/y, 25’i ö/zt/yt/y, 24'ü zt/ö/yt/y, 23’ü ö/zt/blin/y, 20’si zt/ö/zt/y, 17’i zt/ö/blin/y, 15’i ö/zt/bsizn/y, 15’i ö/yt/bsizn/y, 13’ü zt/ö/bsizn/y, 13’ü ö/blin/zt/y, 11’i ö/zt/zt/y, 7'si zt/zt/ö/y, 7'si ö/yt/zt/y, 7'si blin/ö/zt/y 5’i ö/blin/yt/y, 4'ü zt/blin/ö/y, 4'ü blin/yt/ö/y, 3'üu

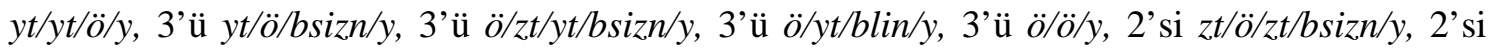
yt/ö/zt/y, 2'si blin/zt/ö/y, 1'i zt/zt/ö/bsizn/y, 1'i zt/yt/ö/bsizn/y, 1'i zt/ö/zt/yt/y, 1'i zt/ö/zt/blin/y, 1'i zt/ö/yt/blin/y, 1'i zt/ö/blin/zt/y, 1’i yt/zt/ö/y, 1'i yt/ö/yt/y, 1’i yt/blin/ö/y, 1'i $\ddot{o} / z t / z t / z t / y, 1$ 'i ö/zt/yt/zt/y, 1'i ö/zt/blin/zt/blin/zt/y, 1’i ö/yt/zt/bsizn/y, 1’i ö/yt/yt/y, 1’i ö/blin/ö/y, 1’i ö/ö/zt/yt/y.

Öznesi eksiltilmiş ve fiil yüklemi çalkalanmamış 508 atasözü olan cümle, 31 farklı öge 
dizimiyle kurulmuş. Dizi sıklıkları esasında bu atasözlerinin öge dizimleri şunlardır: 81'i zt/y, 69'u zt/yt/y, 65'i zt/zt/y, 64'ü zt/blin/y, 34'ü zt/bsizn/y, 34'ü yt/bsizn/y, 33'ü blin/zt/y, 29'u yt/y, 16's1 blin/yt/y, 14'ü blin/y, 8'i zt/yt/bsizn/y, 8'i zt/zt/bsizn/y, 7'si yt/zt/y, 6's1 zt/blin/yt/y, 6's1 zt/blin/zt/y, 5'i yt/blin/y, 4'ü zt/zt/blin/y, 4'ü zt/zt/zt/y, 3'ü bsizn/y, 3'ü yt/yt/y, 3'ü zt/yt/zt/y, 2'si yt/zt/bsizn/y, 2'si blin/zt/ blin/zt/y, 1'i blin/yt/zt/y, 1'i zt/yt/blin/y, 1'i blin/zt/zt/y, 1'i yt/zt/zt/y, 1'i zt/zt/yt/y, 1'i Zt/blin/zt/blin/y, 1'i blin/yt/blin/yt/y, 1'i zt/zt/zt/yt/y.

Öznesi eksiltilmemiş ve fiil yüklemi çalkalanmış 28 atasözü olan cümle, 16 farklı öge dizimi kalıbıyla kurulmuş. Dizi sıklıkları esasında bu atasözlerinin öge dizimleri şunlardır: 8'i zt/ö/y/blin, 3'ü ö/y/zt, 2'si zt/y/ö, 2'si zt/y/ö/zt, 2'si zt/yt/y/ö, 1'i zt/ö/y/yt, 1'i ö/y/yt, 1'i yt/y/ö, 1'i ö/y/blin, 1'i bsizn/y/ö, 1'i zt/zt/y/ö, 1'i ö/blin/y/zt, 1'i ö/bsizn/y/yt, 1'i ö/ö/y/blin, 1'i ö/yt/y/yt, 1'i $z t / z t / b s i z n / y / o ̈$.

Öznesi eksiltilmiş ve fiil yüklemi çalkalanmış 15 atasözü olan cümle, 9 farklı öge dizimi kalıbıyla kurulmuş. Dizi sıklıkları esasında bu atasözlerinin öge dizimleri şunlardır: 4'ü blin/y/zt, 2'si zt/y/blin, 2'si yt/y/zt, 2'si zt/zt/y/yt, 1'i zt/y/yt, 1'i blin/zt/y/zt, 1'i zt/blin/y/yt, 1'i zt/bsizn/y/zt, 1'i zt/y/zt.

Öznesi eksiltilmemiş ve isim yüklemi çalkalanmamış 824 atasözü olan cümle, 11 farklı öge dizimi kalıbıyla kurulmuş. Dizi sıklıkları esasında bu atasözlerinin öge dizimleri şunlardır: 513’ü ö/y, 136's1 yt/ö/y, 89’u zt/ö/y, 40'1 ö/zt/y, 29’u ö/yt/y, 4'ü ö/ö/y, 4'ü ö/ö/ö/y, 4'ü zt/yt/ö/y, 3’ü zt/zt/ö/y, 1’i ö/zt/yt/y, 1’i yt/zt/ö/y.

Öznesi eksiltilmiş ve isim yüklemi çalkalanmamış 12 atasözü olan cümle, 3 farklı öge dizimi kalıbıyla kurulmuş. Dizi sıklıkları esasında bu atasözlerinin öge dizimleri şöyledir: 10’u $z t / y, 1$ 'i $y, 1^{\prime}$ i zt/yt/y.

Öznesi eksiltilmemiş ve isim yüklemi çalkalanmış 9 atasözü olan cümle, 3 farklı öge dizimi kalıbıyla kurulmuş. Dizi sıklıkları esasında bu atasözlerinin öge dizimleri şöyledir: 7'si ö/y/zt, 1’i $\ddot{o} / y / \ddot{o}, 1$ 'i zt/y/ö.

\subsection{Dizi sıklı̆̆ı bakımından öge dizimi kalıpları}

Tek cümlelik Kazakça atasözlerinde tespit edilen öge dizim kalıplarının birleşik dizi sıklıklarına göre sıralanması şöyledir: 1. ö/y (655) 2. zt/ö/y (284) 3. yt/ö/y (247) 4. ö/zt/y (226) 5. ö/yt/y (207) 6. blin/ö/y (99) 7. zt/y (91) 8. ö/blin/y (81) 9. zt/yt/y (70) 10. zt/zt/y (65) 11. zt/blin/y (64) 12. $\mathrm{o} / \mathrm{bsizn} / \mathrm{y}$ (63) 13. yt/bsizn/y (34) zt/bsizn/y (34) 14. blin/zt/y (33) 15. zt/yt/ö/y (32) 16. yt/y (29) 17. $\ddot{0} / \mathrm{zt} / \mathrm{yt} / \mathrm{y}$ (26) 18. zt/ö/yt/y (24) 19. ö/zt/blin/y (23) 20. zt/ö/zt/y (20) 21. zt/ö/blin/y (17) 22. blin/yt/y (16) 23. ö/zt/bsizn/y (15), ö/yt/bsizn/y (15) 24. blin/y (14) 25. zt/ö/bsizn/y (13), ö/blin/zt/y (13) 26. ö/zt/zt/y (11) 27. ö/y/zt (10) zt/zt/ö/y (10) 28. zt/zt/bsizn/y (8), zt/yt/bsizn/y (8), zt/ö/y/blin (8) 29. ö/ö/y (7), yt/zt/y (7), ö/yt/zt/y (7), blin/ö/zt/y (7) 30. zt/blin/zt/y (6), zt/blin/yt/y (6) 31. yt/blin/y (5), ö/blin/yt/y (5) 32. blin/y/zt (4), zt/zt/zt/y (4), zt/zt/blin/y (4), zt/blin/ö/y (4), ö/ö/ö/y (4), blin/yt/ö/y (4) 33. bsizn/y (3), yt/yt/y (3), zt/y/ö (3), zt/yt/zt/y (3), yt/yt/ö/y (3), yt/ö/bsizn/y (3), ö/yt/blin/y (3), ö/zt/yt/bsizn/y (3), 34. yt/y/zt (2), zt/y/blin (2), yt/zt/ö/y (2), zt/zt/y/yt (2), zt/yt/y/ö (2), zt/y/ö/zt (2), yt/zt/bsizn/y (2), yt/ö/zt/y (2), blin/zt/ö/y (2), blin/zt/blin/zt/y (2), zt/ö/zt/bsizn/y (2) 35. zt/y/yt (1), zt/y/zt (1), ö/y/ö (1), ö/y/yt (1), yt/y/ö (1), ö/y/blin (1), (uu/uu)bsizn/y/ö (1), blin/yt/zt/y (1), blin/zt/y/zt (1), blin/zt/zt/y (1), ö/blin/ö/y (1), ö/blin/y/zt (1), ö/bsizn/y/yt (1), ö/ö/y/blin (1), ö/yt/y/yt (1), ö/yt/yt/y (1), yt/blin/ö/y (1), $\mathrm{yt} / \mathrm{o} / \mathrm{yt} / \mathrm{y} \quad(1), \mathrm{yt} / \mathrm{zt} / \mathrm{zt} / \mathrm{y}(1), \mathrm{zt} / \mathrm{blin} / \mathrm{y} / \mathrm{yt} \quad(1), \mathrm{zt} / \mathrm{bsizn} / \mathrm{y} / \mathrm{zt}$ (1), zt/ö/y/yt (1), zt/yt/blin/y (1), zt/zt/y/ö (1), zt/zt/yt/y (1), zt/yt/ö/bsizn/y (1), zt/ö/zt/yt/y (1), zt/ö/zt/blin/y (1), zt/ö/yt/blin/y (1), zt/ö/blin/zt/y (1), ö/zt/zt/zt/y (1), $\ddot{0} / \mathrm{zt} / \mathrm{yt} / \mathrm{zt} / \mathrm{y} \quad(1), \quad \ddot{o} / \mathrm{yt} / \mathrm{zt} / \mathrm{bsizn} / \mathrm{y} \quad(1), \quad \ddot{o} / 0 \ddot{0} / \mathrm{zt} / \mathrm{yt} / \mathrm{y} \quad(1)$, zt/zt/ö/bsizn/y (1), zt/blin/zt/blin/y (1), blin/yt/blin/yt/y (1), zt/zt/zt/yt/y (1), zt/zt/bsizn/y/ö (1), ö/zt/blin/zt/blin/zt/y (1). 


\section{3. Öge sayısı bakımından öge dizimi kalıpları}

Tek cümleden oluşan 2726 (\%100) Kazakça atasözünün bir, iki, üç, dört, beş veya yedi ögeli olduğu belirlendi. Bir ögeli $1(\% 0,037)$ atasözü doğal olarak sadece yüklemden $(\% 0,93)$ oluşmaktadır.

İki ögeli $792(\% 29,05)$ atasözü olan cümle $5(\% 4,63)$ farklı öge dizimi kalıbıyla $(\ddot{o} / y, z t / y$, yt/y, blin/y,bsizn/y) kurulmuş. Bunlardan ö/y ve zt/y öge dizimi kalıpları hem fiil yüklemli hem isim yüklemli atasözlerinde, $y t / y$, blin/y ve bsizn/y öge dizimi kalıpları ise yalnızca fiil yüklemli atasözlerinde tespit edilmiştir. Bu öge dizimi kalıplarının birleşik dizi sıklıkları şöyledir: 792 atasözünden 655'i [ $=142^{f+513}$ ] ö/y dizimiyle, 91'i [ $\left.=81^{f+10}\right] z t / y$ dizimiyle, 29'u yt/y dizimiyle, 14'ü blin/y dizimiyle ve 3’ü bsizn/y dizimiyle kurulmuştur.

Üç ögeli $1573(\% 57,70)$ atasözü olan cümle $30(\% 27,78)$ farklı öge dizimi kalıbıyla

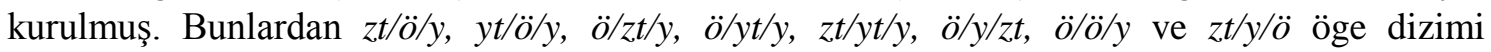
kalıpları hem fiil yüklemli hem isim yüklemli atasözlerinde, diğer öge dizim kalıpları ise ya fiil veya isim yüklemli atasözlerinde tespit edilmiştir. Bu öge dizimi kalıplarının birleşik dizi

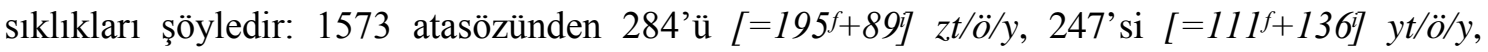
226 's1 [=186f+40i ö/zt/y, 207'si [=178f+29] ö/yt/y, 99'u blin/ö/y, 81'i ö/blin/y, 70'i [=69f+1'] zt/yt/y, 65'i zt/zt/y, 64'ü zt/blin/y, 63'ü ö/bsizn/y, 34'ü zt/bsizn/y, 34'ü yt/bsizn/y, 33'ü blin/zt/y, 16's1 blin/yt/y, 10'u [=3f+7i] ö/y/zt, 7'si yt/zt/y, 7'si [=3f+4] ö/ö/y, 5'i yt/blin/y, 4'ü blin/y/zt, 3'ü

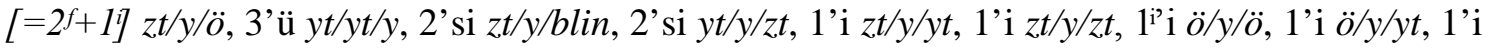
yt/y/ö, 1'i ö/y/blin, 1’i (uu/uu) bsizn/y/ö öge dizimi kalıbıyla kurulmuştur.

Dört ögeli $338(\% 12,40)$ atasözü olan cümle 54 (\%50) farklı öge dizimi kalıbıyla kurulmuş. Bunlardan $z t / y t / o ̈ / y, ~ o ̈ / z t / y t / y, z t / z t / o ̈ / y, y t / z t / o ̈ / y$ ve zt/zt/y/yt öge dizimi kalıpları hem fiil yüklemli hem isim yüklemli atasözlerinde, diğer öge dizim kalıpları ise ya fiil ya da isim yüklemli atasözlerinde tespit edilmiştir. Bu öge dizimi kalıplarının dizi sıklıkları şöyledir: 338 atasözünden 32'si [=28+4i] zt/yt/ö/y, 26's1 [=25+1] ö/zt/yt/y, 24'ü zt/ö/yt/y, 23'ü ö/zt/blin/y, 20'si zt/ö/zt/y, 17’si zt/ö/blin/y, 15’i ö/yt/bsizn/y, 15’i ö/zt/bsizn/y, 13’ü ö/blin/zt/y, 13’ü zt/ö/bsizn/y, 11'i ö/zt/zt/y, 10’u [=7+3i] zt/zt/ö/y, 8'i zt/ö/y/blin, 8'i zt/yt/bsizn/y, 8'i zt/zt/bsizn/y, 7’si blin/ö/zt/y, 7'si ö/yt/zt/y, 6's1 zt/blin/yt/y, 6's1 zt/blin/zt/y, 5'i ö/blin/yt/y, 4'ü blin/yt/ö/y, 4'ü ö/ö/ö/y, 4'ü zt/blin/ö/y, 4'ü zt/zt/blin/y, 4'ü zt/zt/zt/y, 3'ü ö/yt/blin/y, 3'ü yt/ö/bsizn/y, 3'ü

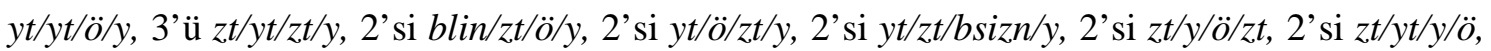
2'si zt/zt/y/yt, 2'si [=1+1i] yt/zt/ö/y, 1'i blin/yt/zt/y, 1'i blin/zt/y/zt, 1'i blin/zt/zt/y, 1'i ö/blin/ö/y, 1'i ö/blin/y/zt, 1'i ö/bsizn/y/yt, 1'i ö/ö/y/blin, 1'i ö/yt/y/yt, 1'i ö/yt/yt/y, 1'i yt/blin/ö/y, 1'i yt/ö/yt/y, 1'i $y t / z t / z t / y, 1$ 'i zt/blin/y/yt, 1'i zt/bsizn/y/zt, 1'i zt/ö/y/yt, 1'i zt/yt/blin/y, 1'i zt/zt/y/ö ve 1 'i zt/zt/yt/y öge dizimi kalıbıyla kurulmuştur.

Beş ögeli $21(0,77)$ atasözü olan cümle $17(\% 15,74)$ farklı öge dizimi kalıbıyla kurulmuş. $\mathrm{Bu}$ öge dizimi kalıplarının hepsi fiil yüklemli atasözlerinde tespit edilmiştir. Bu öge dizimi kalıplarının dizi sıklıkları şöyledir: 21 atasözünden 3'ü ö/zt/yt/bsizn/y, 2'si zt/ö/zt/bsizn/y, 2'si blin/zt/ blin/zt/y, 1'i zt/yt/ö/bsizn/y, 1'i zt/ö/zt/yt/y, 1'i zt/ö/zt/blin/y, 1'i zt/ö/yt/blin/y, 1'i zt/ö/blin/zt/y, 1'i ö/zt/zt/zt/y, 1'i ö/zt/yt/zt/y, 1'i ö/yt/zt/bsizn/y, 1'i ö/ö/zt/yt/y, 1'i zt/zt/ö/bsizn/y, 1’i zt/blin/zt/blin/y, 1'i blin/yt/blin/yt/y, 1'i zt/zt/zt/yt/y, 1'i zt/zt/bsizn/y/ö öge dizimindedir.

Yedi ögeli $1(0,037)$ atasözü tespit edilmiştir. Bu atasözünün de öge dizim kalıbı $(\% 0,93)$ şöyledir: ö/zt/blin/zt/blin/zt/y.

En fazla öge dizimi kalıbı çeşitliliği, 54'le 4 ögeli kalıplarda görülür. Onu sırasıyla 30 öge dizimi kalıbı çeşitliliğiyle 3 ögeli, 17 öge dizimi kalıbı çeşitliliğiyle dört ögeli, 5 öge dizimi kalıbı çeşitliliyle 2 ögeli ve 1'er öge dizimi kalıplarıyla 1 ve 7 ögeli kalıplar izler. Dizi (paradigma) - öge dizimi kalıbı (sentagma) oranında ise ilk sırayı 2 ögeli söz dizim kalıpları 
almakta. 792 atasözü 2 ögeli 5 öge dizim kalıbıyla, 1573 atasözü 3 ögeli 30 öge dizim kalıbıyla, 338 atasözü 4 ögeli 54 öge dizim kalıbıyla, 21 atasözü 5 ögeli 17 öge dizimi kalıbıyla ve 2 atasözü 1'er ögeli 2 farklı öge dizimi kalıbıyla kurulmuş.

Öznesi eksiltilmemiş ve fiil yüklemi çalkalanmamış atasözleri 49, öznesi eksiltilmiş ve fiil yüklemi çalkalanmamış atasözleri 31, öznesi eksiltilmemiş ve fiil yüklemi çalkalanmış atasözleri 16, öznesi eksiltilmiş ve fiil yüklemi çalkalanmış atasözleri 9, öznesi eksiltilmemiş ve isim yüklemi çalkalanmamış atasözleri 11, öznesi eksiltilmiş ve isim yüklemi çalkalanmamış atasözleri 3 ve öznesi eksiltilmemiş ve isim yüklemi çalkalanmış atasözleri 3 farklı öge dizimi kalıbıyla kurulmuş.

14 öge dizimi kalıbı, (ö/y ve zt/y; zt/ö/y, yt/ö/y, ö/zt/y, ö/yt/y, zt/yt/y, ö/y/zt, ö/ö/y, zt/y/ö, zt/yt/ö/y, ö/zt/yt/y, zt/zt/ö/y ve yt/zt/ö/y) hem fiil hem de isim yüklemli atasözlerinin kuruluşunda, 91 öge dizimi kalıbı (yt/y, blin/y, bsizn/y, blin/ö/y, ö/blin/y, zt/zt/y, zt/blin/y, ö/bsizn/y, zt/bsizn/y, yt/bsizn/y, blin/zt/y, blin/yt/y, yt/zt/y, yt/blin/y, blin/y/zt, yt/yt/y, zt/y/blin, yt/y/zt, zt/y/yt, zt/y/zt, ö/y/yt, yt/y/ö, ö/y/blin, (uu/uu) bsizn/y/ö, zt/ö/yt/y, ö/zt/blin/y, zt/ö/zt/y, zt/ö/blin/y, ö/yt/bsizn/y, ö/zt/bsizn/y, ö/blin/zt/y, zt/ö/bsizn/y, ö/zt/zt/y, zt/ö/y/blin, zt/yt/bsizn/y, zt/zt/bsizn/y, blin/ö/zt/y, ö/yt/zt/y, zt/blin/yt/y, zt/blin/zt/y, ö/blin/yt/y, blin/yt/ö/y, zt/blin/ö/y, zt/zt/blin/y, zt/zt/zt/y, ö/yt/blin/y, yt/ö/bsizn/y, yt/yt/ö/y, zt/yt/zt/y, blin/zt/ö/y, yt/ö/zt/y, yt/zt/bsizn/y, zt/y/ö/zt, zt/yt/y/ö, zt/zt/y/yt, blin/yt/zt/y, blin/zt/y/zt, blin/zt/zt/y, ö/blin/ö/y, ö/blin/y/zt, ö/bsizn/y/yt, ö/ö/y/blin, ö/yt/y/yt, ö/yt/yt/y, yt/blin/ö/y, yt/ö/yt/y, yt/zt/zt/y, zt/blin/y/yt, zt/bsizn/y/zt, zt/ö/y/yt, zt/yt/blin/y, zt/zt/y/ö, zt/zt/yt/y, ö/zt/yt/bsizn/y, zt/ö/zt/bsizn/y, blin/zt/ blin/zt/y, zt/yt/ö/bsizn/y, zt/ö/zt/yt/y, zt/ö/zt/blin/y, zt/ö/yt/blin/y, zt/ö/blin/zt/y, ö/zt/zt/zt/y, ö/zt/yt/zt/y, ö/yt/zt/bsizn/y, zt/zt/ö/bsizn/y, zt/blin/zt/blin/y, blin/yt/blin/yt/y, zt/zt/zt/yt/y, zt/zt/bsizn/y/ö, ö/zt/blin/zt/blin/zt/y) yalnız fiil yüklemli atasözlerinin kuruluşunda, 3 öge dizimi kalıbı (y, ö/y/ö, ve ö/ö/ö/y) ise yalnız isim yüklemli atasözlerinin kuruluşunda belirlendi.

3.4. Aynı ögelerle kurulan ancak çalkalanmadan dolayı farklı dizilişteki öge dizimi kalıpları

Tek cümlelik Kazakça atasözlerinde belirlenen 108 öge dizimi kalıbı kendi içinde öge dizimi değişke kalıbı olanlar ve öge dizimi değişke kalıbı olmayanlar biçiminde iki ana gruba ayrılabilir. Öge dizimi değişkesi olanlar da kendi içinde her iki temel ögenin bağımsız dil birimi olarak bulunduğu ve temel ögelerden yalnızca yüklemin bulunduğu alt kümeler şeklinde siniflandirılabilir.

91 öge dizimi kalıbının grup grup aynı ögelerin çalkalanmasıyla oluşmuş öge dizimi kalıbı değişkeleri vardır. Aynı ögelerin çalkalanmasıyla oluşan öge dizimi kalıbı değişkeleri, 27 küme içinde toplanır. 17 öge dizimi kümesinde cümlenin temel ögelerinden özne ve yüklemin her ikisi de bulunurken, 10 öge dizimi kümesinde sadece yüklem vardır.

Cümlenin temel ögelerinden özne ve yüklemin her ikisinin de bulunduğu öge dizimi kümeleri ve bu kümelerdeki öge dizimi kalıbı değişkeleri şunlardır:

Temel ögelerin yanında bir tümleyici öge bulunan 4 öge dizimi kümesi belirlendi. Bunlar: 1 . ZT-Ö-Y kümesi: Bu ögelerin çalkalanmasıyla oluşan 4 farklı öge dizimi kalıbıyla 523 cümle kurulmuş. Yüklemlerinin söz türüne göre bu öge dizimi kalıpları ve dizi sıklıkları şu şekildedir: Fiil yüklemli: I. zt/ö/y (195), II. ö/zt/y (187), III. ö/y/zt (3) IV. zt/y/ö (1); İsim yüklemli: I. zt/ö/y (89), II. ö/zt/y (40), III. ö/y/zt (7), IV. zt/y/ö (1). Fiil ve isim yüklemliler birlikte değerlendirildiğinde öge dizi sıklıkları şöyledir: I. zt/ö/y (284), II. ö/zt/y (226), III. ö/y/zt (10), IV. zt/y/ö (3); 2. $Y T-O ̈-Y$ kümesi: $\mathrm{Bu}$ ögelerin çalkalanmasıyla oluşan 4 farklı öge dizimi kalıbıyla 456 cümle kurulmuş. Yüklemlerinin söz türüne göre bu öge dizimi kalıpları ve dizi sıklıkları şu şekildedir: Fiil yüklemli: I. ö/yt/y (178), II. yt/ö/y (111), III. ö/y/yt (1), IV. yt/y/ö (1); İsim yüklemli: I. yt/ö/y (136); II. ö/yt/y (29). Fiil ve isim yüklemliler birlikte değerlendirildiğinde öge dizi 
sıklıkları şöyledir: I. yt/ö/y (247), I. ö/yt/y (207), III. ö/y/yt (1), IV. yt/y/ö (1); 3. BLİN-Ö-Y kümesi: Bu ögelerin çalkalanmasıyla oluşan 3 farklı öge dizimi kalıbıyla 181 cümle kurulmuş. Bu öge dizimi kalıpları ve dizi sıklıkları şu şekildedir: I. blin/ö/y (99), II. ö/blin/y (81), III. ö/y/blin (1); 4. Ö-BSIZN-Y kümesi: Bu ögelerin çalkalanmasıyla oluşan 2 farklı öge dizimi kalıbıyla 64 cümle kurulmuş. Bu öge dizimi kalıpları ve dizi sıklıkları şu şekildedir: I. ö/bsizn/y (63), II. bsizn/y/ö (1).

Temel ögelerin yanında farklı iki tümleyici öge bulunan 5 öge dizimi kümesi belirlendi. Bunlar: 1. ZT-YT-Ö-Y kümesi: Bu ögelerin çalkalanmasıyla oluşan 8 farklı öge dizimi kalıbıyla 96 cümle kurulmuş. Yüklemlerinin söz türüne göre bu öge dizimi kalıpları ve dizi sıklıkları şu şekildedir: Fiil yüklemli: I. zt/yt/ö/y (28), II. ö/zt/yt/y (25), III. zt/ö/yt/y (24), IV. ö/yt/zt/y (7), V. yt/ö/zt/y (2), VI. yt/zt/ö/y (1), VII. zt/yt/y/ö (2), VIII. zt/ö/y/yt (1); İsim yüklemli: I. zt/yt/ö/y (4), II. ö/zt/yt/y (1), III. yt/zt/ö/y (1). Fiil ve isim yüklemliler birlikte değerlendirildiğinde öge dizi sıklıkları şöyledir: I. zt/yt/ö/y (32), II. ö/zt/yt/y (26), III. zt/ö/yt/y (24), IV. ö/yt/zt/y (7), V. yt/ö/zt/y (2), VI. yt/zt/ö/y (2), VII. zt/yt/y/ö (2), VIII. zt/ö/y/yt (1); 2. Ö-ZT-BLIN-Y kümesi: Bu ögelerin çalkalanmasıyla oluşan 8 farklı öge dizimi kalıbıyla 75 cümle kurulmuş. Bu öge dizimi kalıpları ve dizi sıklıkları şu şekildedir: I. ö/zt/blin/y (23), II. zt/ö/blin/y (17), III. ö/blin/zt/y (13), IV . zt/ö/y/blin (8), V. blin/ö/zt/y (7), VI. zt/blin/ö/y (4), VII. blin/zt/ö/y (2), VIII. ö/blin/y/zt (1); 3. Ö-ZT-BSIZN-Y kümesi: Bu ögelerin çalkalanmasıyla oluşan 2 farklı öge dizimi kalıbıyla 28 cümle kurulmuş. Bu öge dizimi kalıpları ve dizi sıklıkları şu şekildedir: I. ö/zt/bsizn/y (15), II. zt/ö/bsizn/y (13); 4. Ö-YT-BSIZNN-Y kümesi: Bu ögelerin çalkalanmasıyla oluşan 3 farklı öge dizimi kalıbıyla 19 cümle kurulmuş. Bu öge dizimi kalıpları ve dizi sıklıkları şu şekildedir: I. ö/yt/bsizn/y (15), II. yt/ö/bsizn/y (3), III. ö/bsizn/y/yt (1); 5. Ö-BLIN-YT-Y kümesi: Bu ögelerin çalkalanmasıyla oluşan 4 farklı öge dizimi kalıbıyla 13 cümle kurulmuş. Bu öge dizimi kalıpları ve dizi sıklıkları şu şekildedir: I. ö/blin/yt/y (5), II. blin/yt/ö/y (4), III. ö/yt/blin/y (3), IV. yt/blin/ö/y (1).

Temel ögelerin yanında farklı üç tümleyici öge bulunan bir öge dizimi kümesi belirlendi. Bu: 1. Ö-YT-ZT-BSIZN-Y kümesi: Bu ögelerin çalkalanmasıyla oluşan 3 farklı öge dizimi kal1bıyla 5 cümle kurulmuş. Bu öge dizimi kalıpları ve dizi sıklıkları şu şekildedir: I. ö/zt/yt/bsizn/y (3), II. zt/yt/ö/bsizn/y (1), III. ö/yt/zt/bsizn/y (1).

Her iki temel ögenin bulunduğu ve bir ögenin iki defa yer aldığı 7 öge dizimi kümesi belirlendi. Bunlar: 1. Ö-Ö-Y kümesi: Bu ögelerin çalkalanmasıyla oluşan 2 farklı öge dizimi kalıbıyla 8 cümle kurulmuş. Yüklemlerinin söz türüne göre bu öge dizimi kalıpları ve dizi sıklıkları şu şekildedir: Fiil yüklemli: I. ö/ö/y (3), İsim yüklemli: I. ö/ö/y (4), II. ö/y/ö (1). Fiil ve isim yüklemliler birlikte değerlendirildiğinde öge dizi sıklıkları şöyledir: I. ö/ö/y (7), II. ö/y/ö (1); 2. Ö-Ö-BLIN-Y kümesi: Bu ögelerin çalkalanmasıyla oluşan 2 farklı öge dizimi kalıbıyla 2 cümle kurulmuş. Bu öge dizimi kalıpları ve dizi sıklıkları şu şekildedir: I. ö/blin/ö/y (1), II. ö/ö/y/blin (1); 3. YT-YT-Ö-Y kümesi: Bu ögelerin çalkalanmasıyla oluşan 4 farklı öge dizimi kalıbıyla 6 cümle kurulmuş. $\mathrm{Bu}$ öge dizimi kalıpları ve dizi sıklıkları şu şekildedir: I. yt/yt/ö/y (3), II. yt/ö/yt/y (1), III. ö/yt/yt/y (1), IV. ö/yt/y/yt (1); 4. ZT-Ö-ZT-Y kümesi: Bu ögelerin çalkalanmasıyla oluşan 5 farklı öge dizimi kalıbıyla 44 cümle kurulmuş. Yüklemlerinin söz türüne göre bu öge dizimi kalıpları ve dizi sıklıkları şu şekildedir: Fiil yüklemli: I. zt/ö/zt/y (20), II. ö/zt/zt/y (11), III. zt/zt/ö/y (7), IV. zt/y/ö/zt (2), V. zt/zt/y/ö (1); İsim yüklemli: III. zt/zt/ö/y (3). Fiil ve isim yüklemliler birlikte değerlendirildiğinde öge dizi sıklıkları şöyledir: I. zt/ö/zt/y (20), II. ö/zt/zt/y (11), III. zt/zt/ö/y (10), IV. zt/y/ö/zt (2), V. zt/zt/y/ö (1); 5. ZT-Ö-ZT-BSIZZN-Y kümesi: $\mathrm{Bu}$ ögelerin çalkalanmasıyla oluşan 3 farklı öge dizimi kalıbıyla 4 cümle kurulmuş. Bu öge dizimi kalıpları ve dizi sıklıkları şu şekildedir: I. zt/ö/zt/bsizn/y (2), II. zt/zt/ö/bsizn/y (1), III. zt/zt/bsizn/y/ö (1); 6. Ö-YT-ZT-ZT-Y kümesi: Bu ögelerin çalkalanmasıyla oluşan 2 farklı öge 
dizimi kalıbıyla 2 cümle kurulmuş. Bu öge dizimi kalıpları ve dizi sıklıkları şu şekildedir: I. zt/ö/zt/yt/y (1), II. ö/zt/yt/zt/y (1); 7. Ö-ZT-ZT-BLINN-Y kümesi: Bu ögelerin çalkalanmasıyla oluşan 2 farklı öge dizimi kalıbıyla 2 cümle kurulmuş. Bu öge dizimi kalıpları ve dizi sıklıkları şu şekildedir: I. zt/ö/zt/blin/y (1), II. zt/ö/blin/zt/y (1);

Cümlenin temel ögelerinden sadece yüklemin bulunduğu öge dizimi kümeleri ve bu kümelerdeki öge dizimi kalıbı değişkeleri de şunlardır:

Temel ögelerden yüklemin yanında farklı iki tümleyici öge bulunan üç öge dizimi kalıbı kümesi belirlendi. Bunlar: 1. ZT-BLIN-Y kümesi: Bu ögelerin çalkalanmasıly oluşan 4 farklı öge dizimi kalıbıyla 103 cümle kurulmuş. Bu öge dizimi kalıpları ve dizi sıklıkları şu şekildedir: I. zt/blin/y (64), II. blin/zt/y (33), III. zt/y/blin (2), IV. blin/y/zt (4); 2. BLINN-YT-Y kümesi: Bu ögelerin çalkalanmasıyla oluşan 2 farklı öge dizimi kalıbıyla 21 cümle kurulmuş. Bu öge dizimi kalıpları ve dizi sıklıkları şu şekildedir: I. blin/yt/y (16), II. yt/blin/y (5); 3. ZT-YT-Y kümesi: Bu ögelerin çalkalanmasıyla oluşan 4 farklı öge dizimi kalıbıyla 80 cümle kurulmuş. Yüklemlerinin söz türüne göre bu öge dizim kalıpları ve dizi sıklıkları şu şekildedir: Fiil yüklemli: I. zt/yt/y (69), II. yt/zt/y (7), III. yt/y/zt (2), IV. zt/y/yt 1; İsim yüklemli: I. zt/yt/y (1). Fiil ve isim yüklemliler birlikte değerlendirildiğinde öge dizi sıklıkları şöyledir: I. zt/yt/y (70), II. yt/zt/y (7), III. yt/y/zt (2), IV. zt/y/yt (1).

Yüklemin yanında farklı üç tümleyici öge bulunan iki öge dizimi kümesi belirlendi. Bunlar: 1. ZT-YT-BSIZN-Y kümesi: Bu ögelerin çalkalanmasıyla oluşan 2 farklı öge dizimi kalıbıyla 10 cümle kurulmuş. Bu öge dizimi kalıpları ve dizi sıklıkları şu şekildedir: I. zt/yt/bsizn/y (8), II. yt/zt/bsizn/y (2); 2. ZT-BLIN-YT-Y kümesi: Bu ögelerin çalkalanmasıyla oluşan 4 farklı öge dizimi kalıbıyla 9 cümle kurulmuş. Bu öge dizimi kalıpları ve dizi sıklıkları şu şekildedir: I. zt/blin/yt/y (6), II. blin/yt/zt/y (1), III. zt/yt/blin/y (1), IV. zt/blin/y/yt (1).

Temel ögelerden yüklemin bulunduğu ve tümleçlerden birinin iki defa yer aldığı dört öge dizimi kalıbı kümesi belirlendi. Bunlar: 1. ZT/ZT/Y kümesi: Bu ögelerin çalkalanmasıyla oluşan 2 farklı öge dizimi kalıbıyla 66 cümle kurulmuş. Bu öge dizimi kalıpları ve dizi sıklıkları şu şekildedir: I. zt/zt/y (65), II. zt/y/zt (1); 2. ZT-BLIN-ZT-Y kümesi: Bu ögelerin çalkalanmasıyla oluşan 4 farklı öge dizimi kalıbıyla 12 cümle kurulmuş. Bu öge dizimi kalıpları ve dizi sıklıkları şu şekildedir: I. zt/blin/zt/y (6), II. zt/zt/blin/y (4), III. blin/zt/zt/y (1), IV. blin/zt/y/zt (1); 3. ZTZT-BSIZZN-Y kümesi: Bu ögelerin çalkalanmasıyla oluşan 2 farklı öge dizimi kalıbıyla 9 cümle kurulmuş. $\mathrm{Bu}$ öge dizimi kalıpları ve dizi sıklıkları şu şekildedir: I. zt/zt/bsizn/y (8), II. zt/bsizn/y/zt (1); 4. ZT-YT-ZT-Y kümesi: Bu ögelerin çalkalanmasıyla oluşan 4 farklı öge dizimi kalıbıyla 7 cümle kurulmuş. Bu öge dizimi kalıpları ve dizi sıklıkları şu şekildedir: I. zt/yt/zt/y (3), II. zt/zt/yt/y (1), III. yt/zt/zt/y (1), IV. zt/zt/y/yt (2).

Temel ögelerden yüklemin bulunduğu ve iki farklı ögenin ikişer defa yer aldığı bir öge dizimi kalıbı kümesi belirlendi. Bu: 1. BLIN-ZT-BLIN-ZT-Y kümesi: Bu ögelerin çalkalanmasıyla oluşan 2 farklı öge dizimi kalıbıyla 3 cümle kurulmuş. Bu öge dizimi kalıpları ve dizi sıklıkları şu şekildedir: I. blin/zt/blin/zt/y (2), II. zt/blin/zt/blin/y (1).

Aynı ögelerle kurulma bakımından öge dizimi kalıbı değişkesi bulunmayan 15 öge dizimi kalıbı belirlenmiştir. Bunlardan y, zt/ö/yt/blin/y, ö/zt/zt/zt/y, ö/ö/zt/yt/y, zt/zt/zt/yt/y, blin/yt/ blin/yt/y ve ö/zt/blin/zt/blin/zt/y öge dizimi kalıplarının dizi sıklığ1 1'dir. Sadece yüklemden oluşan öge dizimi dışındakilerin öge dizimi kalıbı değişkesinin bulunmaması, belki de dizi sıklıklarının 1 olmasıyla ilgilidir.

Dizi sıklığg 1'in üstünde olup öge dizim kalıbı değişkesi bulunmayan öge dizimi kalıplarının ayırıcı özelliği iki veya üç farklı ögeyle kurulmuş olmalarıdır. İki farklı ögeyle kurulup öge

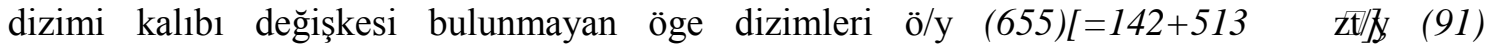


[=81+10 yttyy (29), blin/y (14), bsizn/y (3), yt/yt/y (3), ö/ö/ö/y (4), zt/zt/zt/y (4)'dir. Üç farklı ögeyle kurulup öge dizimi kalıbı değişkesi bulunmayan öge dizilişleri yt/bsizn/y (34) ve zt/bsizn/y (34)'dir.

3.5. Kazakça atasözlerinde öge dizimi eğilimleri ve ölçünlü öge dizimi kalıbı tasarlamaları

Dil tipolojileri çalışmalarında, diller tercih ettikleri öge dizimi bakımından $O / / N / Y$, Ö/Y/N, N/Ö/Y, N/Y/Ö, Y/Ö/N ve Y/N/Ö dilleri olarak (Greenberg 1962; Comrie 2005, 114; Huber 2008, 236) sınıflandırılır. Bu sınıflandırmada, Türk dilinin ölçünlü öge dizimi kalıbının Ö/N/Y olduğu (Greenberg 1962, 63) varsayılır. Ayrıca çalkalayan dil olması sebebiyle Türk dilinde $O ̈ / Y / N$, $N / O ̈ / Y, N / Y / O ̈, Y / O ̈ / N$ ve $Y / N / O ̈$ öge dizimiyle de cümleler kurulabileceği öngörülür.

Cümlede özne ve yüklemin varlığı cümle kurucunun tasarrufunda değildir. Nesne tümlecinin varlığı ise bazı dillerde (msl. İngilizce) cümle kurucunun tasarrufunda değilken, bazı dillerde (msl. Türkçe) cümle kurucunun tasarrufundadır. Ayrıca öznenin cümle varlığı bazı dillerde ancak bağımsız biçim birimleriyle işaretlenirken, bazı dillerde aynı anda hem bağımsız hem bağımlı biçim birimleriyle bazen de sadece bağımlı biçim birimle işaretlenebilmektedir. İște bağımlı biçim birimlerle de işaretlenebilen dillerde, özne, cümle kurucunun tasarrufuna bağlı olarak cümlede bağımsız biçim birim biçiminde de yer alabilmektedir.

Bu cümleden bir dilinin öge dizimi eğiliminin belirlenmesi, başka diller için geçerli olan söz dizimsel ölçütlere göre değil, kendi söz dizimsel özellikleri dikkate alınarak belirlenecek ölçütlere göre belirlenmelidir. Yukarıda verilen öge dizilim kalıpları özne, yüklem ve nesne tümlecinin bağımsız biçim birim olarak dil kullanıcısının tasarrufu dışında cümlede yer aldığı dillerin öge dizim eğilimlerini belirlemek için yeterli olabilir. Ancak bu öge dizimi kalıpları özne ve nesne tümlecinin cümlede bağımsız dil birimi olarak varlığı cümle kurucunun tasarrufunda olduğu Türk dili gibi dillerdeki öge dizimlerini ve tercihlerini sağlıklı belirlemede yeterli olacağı şüphelidir. Yalnızca özne, yüklem ve nesne tümleci bulunan cümlelerin öge dizim eğilimleri dikkate alınarak, özne ve nesne tümlecinin bağımsız dil birimi olarak cümledeki varlığı cümle kurucunun tasarrufunda olduğu dillerin, özelde Türk dilinin ve onun bir türü olan Kazakçanın öge dizim eğilimini belirlemekte kapsayıcı olmayacaktır.

Tek cümleden oluşan Kazakça atasözlerindeki öge dizimi eğilimleri, kendi söz dizimsel özellikleri dikkate alındığında şu sonuçlar çıkmaktadır:

Tek cümlelik Kazakça atasözlerinde iki farklı ögeyle kurulmuş iki ögeli öge dizim kalıpları ö/y (655), zt/y (91), yt/y (29), blin/y (14) ve bsizn/y (3)dir. Çözümlenen 2726 tek cümlelik atasözleri arasında, bu öge dizim kalıplarının çalkalamayla oluşabilecek $y / o ̈, y / z t, y / y t, y / b l i n$ ve $y / b s i z n$ öge dizim kalıbı değişkelerine rastlanmadı. Aynı durum iki farklı ögeyle kurulan ancak yüklem dışındaki ögenin iki veya üç defa tekrar edildiği yt/yt/y (3), ö/ö/ö/y (4), zt/zt/zt/y (4) öge dizimi kalıpları için de geçerlidir.

İki farklı ögeyle, iki ögeli cümle olarak kurulan Kazakça tek cümlelik atasözlerinde yüklem sürekli cümlenin sonundadır. Bağımsız dil birimi olarak cümlede yer alması cümle kurucunun tasarrufunda olan ögeler ise cümlenin başındadır. Bu bilgilerden yola çıkılarak iki farklı ögeyle kurulan özellikle iki ögeli Kazakça atasözleri için, ölçünlü öge dizimi kalıbının temel ögelerle kurulanlarda Ö/Y ve yüklemin yanında bir tümleçle kurulanlarda N/Y olduğu söylenebilir.

Cümlenin temel ögeleri özne ve yüklemin yanında bir tümleyici ögeyle kurulan Ö-ZT-Y kümesindeki (523,\%100) öge dizimi kalıbı değişkeleri ve genel dizi sıklıkları I. zt/ö/y (284, \%54,30), II. ö/zt/y (226, \%43,21), III. ö/y/zt (10, \%1,91), IV. zt/y/ö (3, \%0,58); Ö-YT-Y kümesindeki (456, \%100) öge dizimi kalıbı değişkeleri ve genel dizi sıklıkları I. yt/ö/y (247, \%54,17), II. ö/yt/y (207, \%45,39), III. ö/y/yt (1, \%0,22), IV. yt/y/ö $(1, \% 0,22)$; Ö-BLİN-Y 
kümesindeki (181, \%100) öge dizimi kalıbı değişkeleri ve genel dizi sıklıkları I. blin/ö/y (99, \%54,70), II. ö/blin/y (81, \%45,75), III. ö/y/blin (1, \%0,55) ve Ö-BSİZN-Y kümesindeki (64, \%100) öge dizimi kalıbı değişkeleri ve genel dizi sıklıkları I. ö/bsizn/y (63, \%98,44), II. bsizn/y/ö (1, \%1,56) biçimindedir.

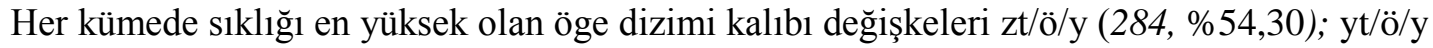
(247, \%54,17), blin/ö/y $(99, \% 54,70)$ ve ö/bsizn/y $(63, \% 98,44) ’ d i r$. Kendi kümesinde dizi s1klığ1 en yüksek olan bu öge dizim kalıplarından $z t / o ̈ / y, y t / o ̈ / y$ ve blin/ö/y öge dizimi kalıplarında, ilk öge görüldüğü üzere özne değil zarf tümleci, yer tümleci veya belirtili nesne tümlecidir. Özne sadece ö/bsizn/y diziminde ilk ögedir.

Dizi sıklığı en yüksek yukarıdaki gibi üç ögeli öge dizim kalıplarında görülen cümleye özneyle başlamama eğilimi, incelen tek cümlelik bütün atasözleri dikkate alındığında da ortaya çıkmaktadır. İncelenen 2726 tek cümlelik atasözünün 2191'inde $(\% 80,37)$ özne bağımsız bir dil birimi olarak bulunur. Özne, bağımsız bir dil birimi olarak bulunduğu 2191 cümleden 667'sinde, yüklemin cümle başına çalkalanma kısıtlığından dolayı zorunlu olarak cümlenin ilk ögesidir. Zorunlu ilk öge olduğu öge dizim kalıpları ö/y (655), ö/ö/y (7), ö/ö/ö/y (4) ve ö/y/ö (1)’dir. Geriye kalan $1523(\% 100)$ cümleden 721 'inde $(\% 47,34)$ cümleye özneyle başlanmış [1. ö/zt/y (226), 2. ö/yt/y (207), 3. ö/blin/y (81), 4. ö/bsizn/y (63), 5. ö/zt/yt/y (26), 6. ö/zt/blin/y (23), 7. ö/yt/bsizn/y (15), 8. ö/zt/bsizn/y (15), 9. ö/blin/zt/y (13), 10. ö/zt/zt/y (11), 11. ö/y/zt (10), 12. ö/yt/zt/y (7), 13. ö/blin/yt/y (5), 14. ö/yt/blin/y (3), 15. ö/zt/yt/bsizn/y (3), 16. ö/y/blin (1), 18. ö/y/yt (1), 19. ö/blin/ö/y (1), 20. ö/blin/y/zt (1), 21. ö/bsizn/y/yt (1), 22. ö/ö/y/blin (1), 23. ö/yt/y/yt (1), 24. ö/yt/yt/y (1), 25. ö/ö/zt/yt/y (1), 26. ö/yt/zt/bsizn/y (1), 27. ö/zt/yt/zt/y (1), 28. ö/zt/zt/zt/y (1), 29. ö/zt/blin/zt/blin/zt/y (1)], 803'ünde $(\% 52,66)$ ise cümleye özneyle başlanmamış [1. zt/ö/y (284), 2. yt/ö/y (247), 3. blin/ö/y (99), 4. zt/yt/ö/y (32), 5. zt/ö/yt/y (24), 6. zt/ö/zt/y, (20), 7. zt/ö/blin/y (17), 8. zt/ö/bsizn/y (13), 9. zt/zt/ö/y (10), 10. zt/ö/y/blin (8), 11. blin/ö/zt/y (7), 12. blin/yt/ö/y (4), 13. zt/blin/ö/y (4), 14. yt/ö/bsizn/y (3), 15. yt/yt/ö/y (3), 16. zt/y/ö (3), 17. blin/zt/ö/y (2), 18. yt/ö/zt/y (2), 19. yt/zt/ö/y (2), 20. zt/ö/zt/bsizn/y (2), 21. zt/y/ö/zt (2), 22. zt/yt/y/ö (2), 23. bsizn/y/ö (1), 24. yt/blin/ö/y (1), 25. yt/ö/yt/y (1), 26. yt/y/ö (1), 27. zt/ö/blin/zt/y (1), 28. zt/ö/y/yt (1), 29. zt/ö/yt/blin/y (1), 30. zt/ö/zt/blin/y (1), 31. zt/ö/zt/yt/y (1), 32. zt/yt/ö/bsizn/y (1), 33. zt/zt/bsizn/y/ö (1), 34. zt/zt/ö/bsizn/y (1), 35. zt/zt/y/ö (1)].

Özellikle çalkalayan dillerde, ölçünlü öge dizimi, kurulan cümlelerdeki öge dizimlerinin dizi sıklıkları dikkate alınarak varsayılsa gerek. Tek cümlelik Kazakça atasözlerinde yüklemin \%98,09 oranında öge diziminin sonunda olduğu ve öznenin bağımsız dil birimi olarak bulunduğu cümlelerde, cümleye \%52,66 oranında özne dışında bir ögeyle başlandığı çözümlemeler sonunda belirlendi. Bu bilgilerle tasarlanacak öznenin de bağımsız biçim birim olarak yer aldığ ölçünlü üç ögeli bir öge diziminde yüklem sonda, özne ise onun öncesinde, tümleç ise cümlenin ilk ögesidir. Sonuçta da temel ögelerin yanında bir tümleçle kurulan Kazakça tek cümlelik atasözlerinin söz dizimi eğliminin $N / O ̈ / Y$ diziminden yana olduğu görülür. Ölçünlü öge dizimi, tercihe göre belirleniyorsa, temel ögelerin yanında bir tümleçle kurulan Kazakça tek cümlelik atasözlerinin ölçünlü öge dizimi $N / O ̈ / Y$ 'dir.

Temel ögelerin yanında farklı iki tümleyici öge bulunan 5 öge dizimi kümesinden. ZT-YTÖ-Y'de en yüksek dizi sıklı̆̆ 1 zt/yt/ö/y (32) öge dizimi kalıbında, Ö-ZT-BLINN-Y'de en yüksek dizi sıklığ1 ö/zt/blin/y (23) öge dizimi kalıbında, Ö-ZT-BSIZZN-Y' en yüksek dizi s1klığ ö/zt/bsizn/y (15) öge dizimi kalıbında, Ö-YT-BSIZN-Y'de en yüksek dizi sıklığı ö/yt/bsizn/y (15) öge dizimi kalıbında ve Ö-BLIN-YT-Y’de en yüksek dizi sıklığı ö/blin/yt/y (5) öge dizimi kalıbındadır. Dizi sıklığı dikkate alındığında temel ögelerin yanında farklı iki tümleçle kurulan Kazakça atasözlerinde öge dizimi tercihinin $O / N / N / Y$ 'den yana olduğu görülür. 
Temel ögelerin yanında farklı üç tümleyici öge bulunan tek öge dizimi kümesi olan $\ddot{O}-Y T$ $Z T-B S i Z N-Y$ 'de en yüksek dizi sıklığı ö/zt/yt/bsizn/y (3) öge dizimi kalıbındadır. Dizi sıklı̆̆ dikkate alındığında temel ögelerin yanında farklı üç tümleçle kurulan Kazakça atasözlerinde öge dizimi tercihi $O / N / N / N / Y$ ' den yanadır.

Temel ögelerden yüklemin yanında farklı iki tümleç bulunan öge dizimi kalıbı kümelerinden $Z T$-BLIN-Y'de en yüksek dizi sıklığı zt/blin/y (64) öge dizimi kalıbında, BLIN-YT-Y'de en yüksek dizi sıklığı blin/yt/y (16) öge dizimi kalıbında ve $Z T-Y T-Y$ 'de en yüksek dizi sıklığı zt/yt/y (70) öge dizimi kalıbındadır. Dizi sıklığı dikkate alındığında temel ögelerden yüklemin yanında farklı iki tümleçle kurulan Kazakça atasözlerinde öge dizimi tercihinin $N / N / Y$ 'den yana olduğu görülür.

Temel ögelerden yüklemin yanında farklı üç tümleç bulunan öge dizimi kalıbı kümelerinden $Z T-Y T-B S I Z Z N-Y$ 'de en yüksek dizi sıklığı zt/yt/bsizn/y (8) öge dizimi kalıbında, ve ZT-BLIN-YT$Y$ 'de en yüksek dizi sıklığı zt/blin/yt/y (6) öge dizimi kalıbındadır. Dizi sıklığı dikkate alındığında temel ögelerden yüklemin yanında farklı üç tümleçle kurulan Kazakça atasözlerinde öge dizimi tercihinin $N / N / N / Y$ ' den yana olduğu görülür.

\section{Sonuç}

Kazakların sezgisel dil bilgisi bilgileriyle ortak olarak kurdukları 2726 tek cümlelik atasözünün öge ve öge dizimi kalıbı incelemesi neticesinde, ortak kurulan cümlelerin \%69 oranında fiil, $\% 31$ oranında isim yüklemli olduğu ve yüklemi çalkalanmayan cümlelerin $\% 98,09$, çalkalanan cümlelerin ise $\% 1,91$ oranında olduğu belirlenmiştir.

Çözümlenen atasözleri içinde, öznenin bağımsız dil birimi olarak var olduğu cümleler $\% 80,34$, var olmadığı cümleler ise \%19,66 oranındadır. Fiil yüklemli cümlelerde (\%27,86), isim yüklemli cümlelere göre $(\% 1,42)$ özne eksiltilme oranı, dikkati çekecek ölçüde yüksektir.

Atasözleri eş zamanlı ve art zamanlı aynı dili konuşanların ortak cümleleri olduğu için kişiler, atasözlerinin öge dizimlerine müdahale etmezler. Bundan dolayı çalkalayan bir dilin ölçünlü öge diziminin belirlenmesinde atasözleri önemli bir malzeme olsa gerek. Bu bağlamda, tek cümlelik Kazaça atasözlerinden temel ögelerle kurulanlarında öge dizim tercihinin Ö/Y öge dizimi kalıbından yana, yüklemin yanında bir tümleçle kurulanlarda N/Y öge dizimi kalıbından yana, temel ögelerin yanında bir tümleçle kurulanlarda N/Ö/Y öge dizimi kalıbından yana, temel ögelerin yanında farklı iki tümleçle kurulanlarda Ö/N/N/Y öge dizimi kalıbından yana, temel ögelerin yanında farklı üç tümleçle kurulanlarda Ö/N/N/N/Y öge dizimi kalıbından yana, temel ögelerden yüklemin yanında farklı iki tümleçle kurulanlarda N/N/Y öge dizimi kalıbından yana ve temel ögelerden yüklemin yanında farklı üç tümleçle kurulanlarda N/N/N/Y öge dizimi kalıbından yana olduğu tespit edilmiştir.

İstatistiki verilere dayanılarak temel ögelerin yanında bir tümleçle kurulan Kazakça atasözleri için tercih edildiği belirlenen $N / O ̈ / Y$ ölçünlü öge dizimi, dil tipolojileri üzerine yapılan çalışmalarda Türk dili için varsayılan Ö/N/Y ölçünlü öge dizimi kalıbıyla uyuşmamaktadır. Ayrıca yine genel dil bilimi çalışmalarında, çalkalayan bir dil olmasından dolayı Türk dilinde var olabileceği öngörülen $\mathrm{Y} / \mathrm{O} / \mathrm{N}$ ve $\mathrm{Y} / \mathrm{N} / \mathrm{O}$ öge dizimlerine, çözümlenen atasözlerinde hiç rastlanmamıştır.

Özelde Kazakçanın, genelde Türk dilinin öge dizimi tercihlerinin ve ölçünlü öge diziminin ne olduğu sorusuna cevap, eş zamanlı ve art zamanlı milletin ortak dil ürünleri olan kalıplaşmış sözleri, özellikle de atasözlerini ve dil ilişkilerinin en az seviyede yaşandığı ortamlarda oluşturulan metinlerdeki cümlelerin öge dizimi kalıpları belirlenip istatistiki sonuçlar çıkarılarak verilebilir. 


\section{KAYNAKÇA}

Bussmann H. (1996). Routledge Dictionary of Language and Linguistics. New York 1996.

Comrie B. (2005). Dil Evrensellikleri ve Dilbilim Tipolojisi. Çev. İ. Ulutaş. İstanbul 2008.

Éldebekov T. (red.) (2010). Babalar Sözi 65. Tom, Kazak Makal Mételderi, Astana, Foliant

Gökdayı H. (2008). “Türkçede Kalıp Sözler”. Bilig 44 (Kış/2008) 89-110.

Greenberg J. H. (1963). "Some Universals of Grammar with Particular Reference to the Order of Meaningful Elements”. Universals of Language (1963) 73-113. Cambridge.

Huber E. (2008). Dilbilime Giriş, Multilingual. İstanbul 2008.

Karaağaç G. (2013). Dil Bilimi Terimleri Sözlüğ̈̈. Ankara 2013.

Ross J. R. (1967). Constraints on Variables in Syntax. PhD Dissertation. MIT. Cambridge 1967.

Tomlin R. S. (1986). Basic word order: functional principles. Croom Helm.

Yavuz N. (2012). İkinci Dil Olarak Türkçe ve Japoncada Çalkalamanın Edinimi. Yayımlanmamış Doktora Tezi. Ankara Üniversitesi, Sosyal Bilimler Enstitüsü, Dilbilim Anabilim Dalı. Ankara 2012 